\title{
New and interesting chaetothyrialean fungi from Spain
}

\author{
H. Madrid ${ }^{1}$, M. Hernández-Restrepo ${ }^{2,3}$, J. Gené ${ }^{4}$, J. Cano $^{4}$, J. Guarro ${ }^{4}$ and V. Silva ${ }^{5}$
}

\footnotetext{
${ }^{1 .}$ Center for Genomics and Bioinformatics and Science Faculty, Mayor University, Camino La Piramide 5750, Huechuraba, Santiago, Chile

2.Evolutionary Phytopathology, CBS-KNAW Fungal Biodiversity Centre, Utrecht, The Netherlands

${ }^{3 .}$ Department of Microbiology and Plant Pathology, Forestry and Agricultural Biotechnology Institute (FABI), University of Pretoria, Pretoria, South Africa

4. Mycology Unit, Medical School and IISPV, Universitat Rovira i Virgili, Reus, Spain

${ }^{5 .}$ Science Faculty, Mayor University, Camino La Piramide 5750,, Huechuraba, Santiago, Chile
}

\begin{abstract}
In the course of taxonomic studies on saprobic microfungi from Spain, several slow-growing, dematiaceous hyphomycetes were isolated from soil, submerged plant material and river sediments. Sixteen of these strains were identified as members of the ascomycete order Chaetothyriales on the basis of morphology and DNA sequence analyses of the internal transcribed spacer region and partial large subunit ribosomal RNA gene. These included three novel species (Cladophialophora pseudocarrionii, Cyphellophora chlamydospora, and Rhinocladiella amoena) and five interesting, little-known or clinically-relevant species (Cyphellophora suttonii, Exophiala aquamarina, E. lacus, E. radicis, and Rhinocladiella similis). In addition, Exophiala oligosperma, an emerging opportunistic fungus, was found for the first time in an aquatic freshwater environment (river sediments). Cladophialophora pseudocarrionii resembles $C$. carrionii in the branching pattern of its conidial chains, but differs from the latter species in its inability to grow at $30^{\circ} \mathrm{C}$. Cyphellophora chlamydospora differs from other species of the genus in the absence of conidiation, producing only chlamydospores in vitro. Rhinocladiella amoena shows branched conidiophores similar to those of $R$. anceps, $R$. atrovirens, $R$. basitona and $R$. similis, but differs from them in conidial shape and size. The ex-type strain of Phialophora livistonae, included in the phylogenetic study, clustered with high statistical support with members of the genus Cyphellophora and is transferred to this genus.
\end{abstract}

\section{Keywords}

Black yeasts, Chaetothyriales, Cladophialophora, Cyphellophora, Exophiala, Rhinocladiella 


\section{Introduction}

Chaetothyriales is a species-rich, ecologically diverse order of Ascomycota (Geiser et al. 2006; Gueidan et al. 2014). It includes saprophytes associated with soil and decaying plant material (Iwatsu 1984; Decock et al. 2003; Badali et al. 2011), numerous clinically-relevant species (de Hoog et al. 2000; Badali et al. 2008; Feng et al. 2012), and fungi causing disease in aquatic, cold-blooded animals (de Hoog et al. 2011; Vicente et al. 2012). In addition, a number of species in this order are associated with living plants, occurring either as apparently harmless epi- or endophytes (Narisawa et al. 2007; Chomnunti et al. 2012) or as pathogens (Crous et al. 2006, 2007b; Gueidan et al. 2014). Some Chaetothyriales are abundant in humid indoor habitats (Matos et al. 2002; Döğen et al. 2013), but other species, by contrast, colonize harsh environments where they have to cope with drought, scarce nutrient availability, extreme temperatures and high UV-light exposure (Gueidan et al. 2008; Tsuneda et al. 2011). This order has also received special attention due to the recent discovery of mutualistic interactions with ant species (Voglmayr et al. 2011; Nepel et al. 2014), and to the ability of certain species to degrade aromatic hydrocarbon contaminants (Prenafeta-Boldú et al. 2001; Badali et al. 2011).

Chaetothyrialean fungi may be difficult to isolate from environmental samples due to their slow growth rates. On common mycological media, they are usually overgrown by fastgrowing molds such as Aspergillus, Penicillium or members of the Mucorales. Therefore, special isolation techniques may be necessary. Previous authors have successfully implemented methods using experimental inoculations in laboratory animals (Gezuele et al. 1972; Dixon et al. 1980), high incubation temperatures (Sudhadham et al. 2008), extraction with mineral oil (Satow et al. 2008; Vicente et al. 2008), enrichment on atmospheres with aromatic hydrocarbons (Prenafeta-Boldú et al. 2001; Zhao et al. 2010) and media containing cycloheximide (Salgado et al. 2004). In our experience, media with cycloheximide proved to be very useful to isolate members of the Chaetothyriales. Using such media, we isolated the recently described taxa Cladophialophora multiseptata, Cyphellophora catalaunica, and Knufia tsunedae (Crous et al. 2013). In this study, we report the results of a morphological and molecular characterization of 16 strains of chaetothyrialean fungi obtained with the aid of cycloheximide-containing media, from diverse Spanish environmental samples.

\section{Materials and methods}

\section{Sampling areas, fungal isolation and strains studied}

Samples of soil, submerged plant material and river sediments were collected in forest areas and urban sites of five Spanish autonomic communities, i.e. Aragon, Asturias, Castile-La Mancha, Castile-Leon, and Catalonia. Samples were placed into polyethylene bags and kept in a refrigerator at $4-7^{\circ} \mathrm{C}$ until processed. Approximately $1 \mathrm{~g}$ of each sample was diluted in $9 \mathrm{ml}$ of sterile water and a Digralsky spreader was used to spread a $500-\mu \mathrm{L}$ aliquot of the mix on the surface of plates with potato-dextrose agar (PDA; Difco Laboratories, USA) or dichloran rose-bengal chloramphenicol agar (DRBC; Oxoid, UK), both supplemented with cycloheximide at a final concentration of $0.1 \mathrm{mg} / \mathrm{mL}$. The plates were incubated at $25^{\circ} \mathrm{C}$ in the dark and observed weekly. Pure cultures were obtained by transferring conidia from slow-growing, darkly pigmented colonies growing on the primary cultures to PDA plates, 
with the aid of a sterile dissection needle. These PDA plates were incubated at $25^{\circ} \mathrm{C}$ for 14 days in the dark and then DNA extraction and subculturing onto other media for morphological studies were performed. Strains were preserved in the fungal culture collections of the Medicine Faculty, Rovira i Virgili University, Reus, Spain (FMR collection), and at the CBS-KNAW Fungal Biodiversity Centre, Utrecht, The Netherlands (CBS).

\section{Phenotypic characterization}

Colony morphology was studied on malt extract agar (MEA; Oxoid) and oatmeal agar (OA; $30 \mathrm{~g}$ filtered oat flakes, $20 \mathrm{~g}$ agar, $1 \mathrm{~L}$ distilled water) after 14 days at $24{ }^{\circ} \mathrm{C}$ in the dark. Cardinal growth temperatures were determined from cultures on MEA at temperatures ranging from 6 to $36^{\circ} \mathrm{C}$ at intervals of $6{ }^{\circ} \mathrm{C}$. Microscopic morphology was studied from slide cultures on $\mathrm{OA}$ at $24^{\circ} \mathrm{C}$ after 21 days. For one strain, i.e. CBS 127581, which did not sporulate on OA, slide cultures were also prepared on MEA and potato-carrot agar (PCA; $20 \mathrm{~g}$ of potatoes, $20 \mathrm{~g}$ of carrots, $20 \mathrm{~g}$ of agar, $1 \mathrm{~L}$ of distilled water). Photomicrographs were obtained using a Zeiss Axioskop 2 Plus light microscope.

\section{DNA sequence analyses}

DNA extraction and purification was performed directly from colonies on PDA by following the Fast DNA kit protocol (Bio 101, Vista, CA, USA), with the homogenization step repeated five times with a FastPrep FP120 instrument (Thermo Savant, Holbrook, NY, USA). The internal transcribed spacer region (ITS) and the D1/D2 domains of the large subunit rRNA gene (LSU) were sequenced with the primer pairs ITS5/ITS4 and NL1/NL4 as described by White et al. (1990) and O'Donnell (1993), respectively. Purification of PCR products was carried out with the GFXTM PCR DNA kit (Pharmacia Biotech, Cerdanyola, Spain) and these were stored at $-20{ }^{\circ} \mathrm{C}$ until sequencing. PCR products were sequenced with the same primers used for amplification and following the Taq Dydeoxy Terminator cycle sequencing kit protocol (Applied Biosystems, Gouda, The Netherlands). DNA sequencing reaction mixtures were analyzed on a 310 DNA sequencer (Applied Biosystems). Consensus sequences were obtained from the complementary sequences of each strain using the SeqMan software (Lasergene, Madison, WI, USA). BLAST searches (Altschul et al. 1990) were performed with the ITS and LSU sequences of the strains studied in order to compare them with those of species deposited in GenBank. For molecular species identification, percent identities of just the ITS locus were considered, because it offers a higher resolution than the relatively conserved LSU gene (Iwen et al. 2002). If the identity of the ITS sequence of a studied strain to its closest match was $\geq 99 \%$, they were considered conspecific (Zeng et al. 2007). In rare cases where more than one species yielded $99 \%$ identity, but none of them reached $100 \%$, the studied strain was identified only to genus level.

The level of variation among ITS sequences of all taxa included in this study was too high to obtain a reliable, non-ambiguous alignment. Therefore, the phylogenetic studies included a general LSU-based tree with all new species and records, and related members of Chaetothyriales (Fig. 1), and four ITS-based phylogenetic trees for specific genera, including: (1) Cladophialophora (Fig. 2), (2) Cyphellophora (Fig. 3), (3) Exophiala (Fig. 4), and (4) Rhinocladiella and morphologically similar chaetothyrialean genera, such as Fonsecaea, Thysanorea, and Veronaea (Fig. 5), all of which produce sympodial, denticulate 
conidiogenous cells (de Hoog et al. 2000; Arzanlou et al. 2007). The Cyphellophora and Rhinocladiella ITS trees included all members of those genera for which ITS sequences are currently available at GenBank. However, in the Cladophialophora and Exophiala ITS trees, the ingroup only included species belonging in Herpotrichiellaceae, the family which includes the type species of these genera, i.e. C. carrionii and E. salmonis, respectively (de Hoog et al. 2000). BLAST searches and previous literature (Réblová et al. 2013; Gueidan et al. 2014) revealed that several species in these genera are related to other families in Chaetothyriales. Excluded members of Cladophialophora include three species in Epibryaceae (C. humicola, C. minutissima, and C. sylvestris), three species in Trichomeriaceae (C. modesta, C. proteae and C. pucciniophila), and two species related to Cyphellophoraceae ( $C$. hostae and $C$. scillae, the latter used as outgroup). Excluded Exophiala spp. include E. eucalyptorum (Chaetothyriaceae), and E. encephalarti and $E$. placitae (both members of Trichomeriaceae, of which the latter was used as outgroup). ITS and LSU sequences were aligned with the MUSCLE webserver (http://www.ebi.ac.uk/Tools/msa/muscle/, Edgar 2004) and then adjusted manually with a text editor to correct misalignments and exclude ambiguous regions. Phylogeny reconstructions were performed with the maximum likelihood method with MEGA 6 (Tamura et al. 2013), using the best DNA substitution models chosen by that software. The statistical support for the groupings was assessed by bootstrap analysis of 1000 replicates. The DNA sequences and alignments generated during this study were deposited in GenBank (Table 1) and TreeBASE (study accession URL: http://purl.org/phylo/treebase/phylows/study/TB2:S18979), respectively. 


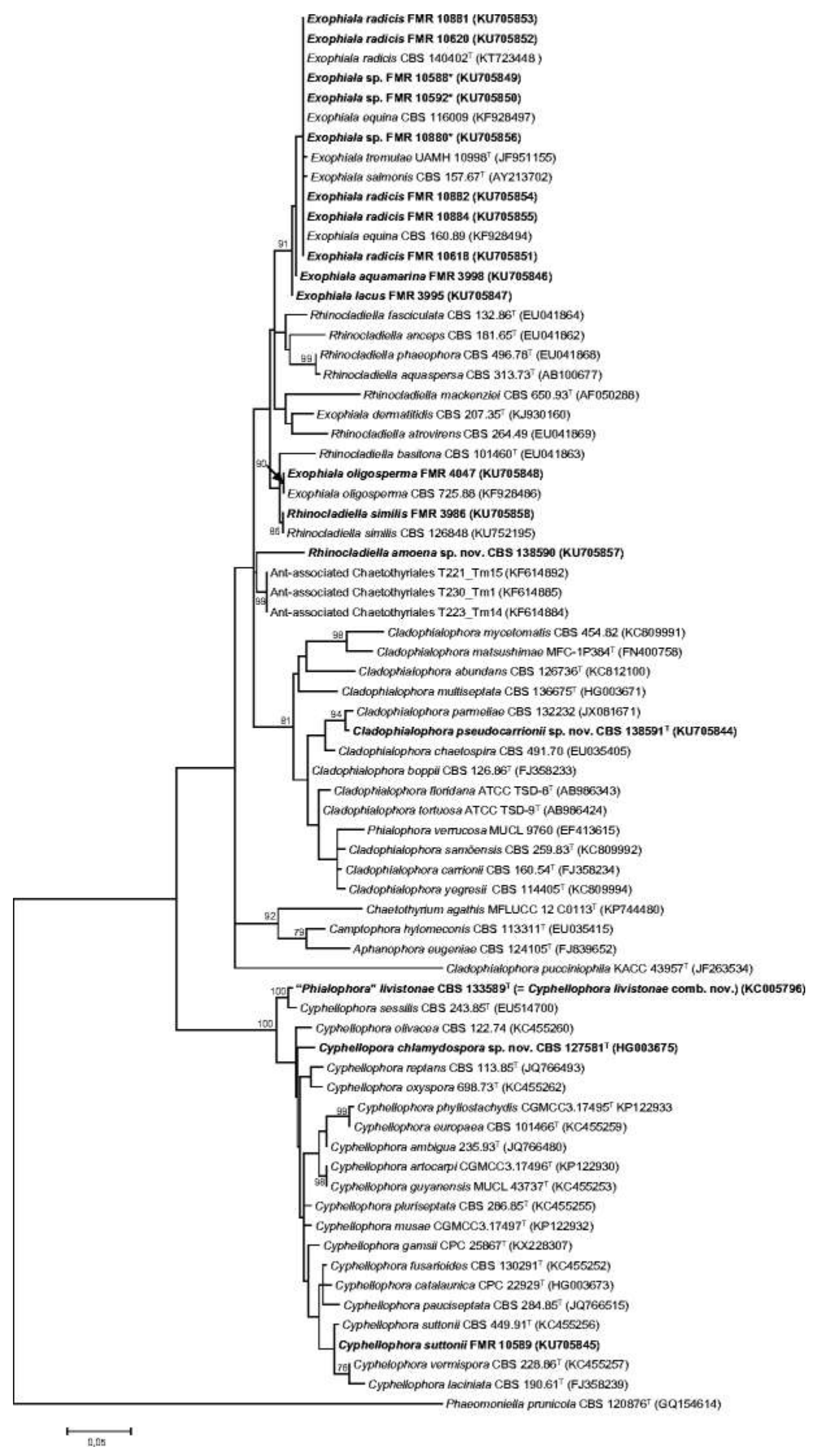

Fig. 1. Maximum likelihood tree constructed with partial sequences of the LSU rDNA of chaetothyrialean fungi isolated during this study and related reference strains. Branch lengths are proportional to distance. Bootstrap values $\geq 70 \%$ are shown near the internodes. Phaeomoniella prunicola was used as outgroup. ${ }^{\top}$ ex-type strain; * Exophiala strains requiring data from additional loci for a definitive species-level identification 


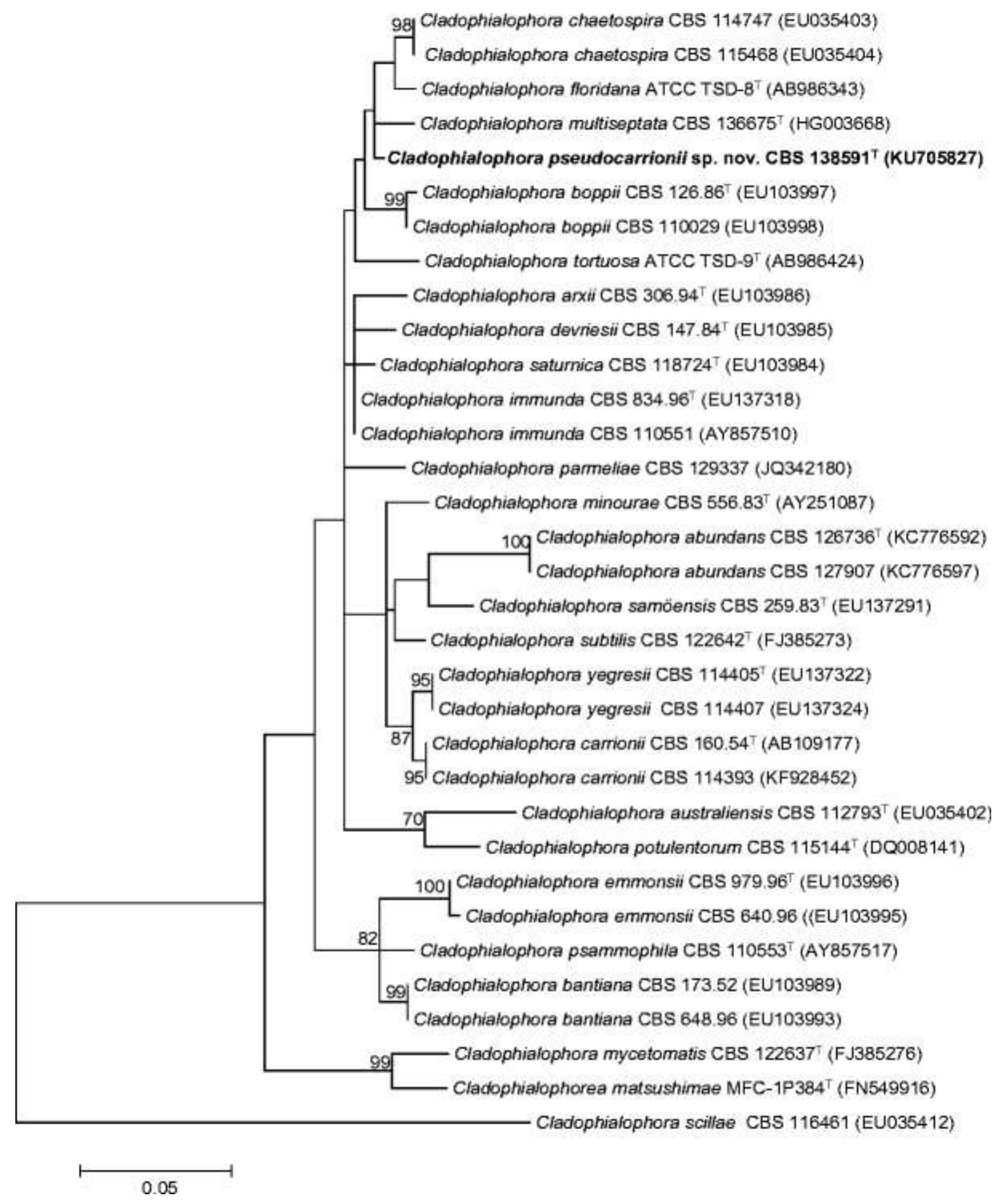

Fig. 2. Maximum likelihood tree constructed with partial sequences of the ITS region of Cladophialophora spp. Branch lengths are proportional to distance. Bootstrap values $\geq 70 \%$ are shown near the internodes. The ingroup includes all species of this genus belonging to Herpotrichiellaceae for which DNA sequences are available at GenBank. Cladophialophora scillae, a species related to Cyphellophoraceae (Gueidan et al. 2014), was used as outgroup. ${ }^{\top}$ ex-type strain 


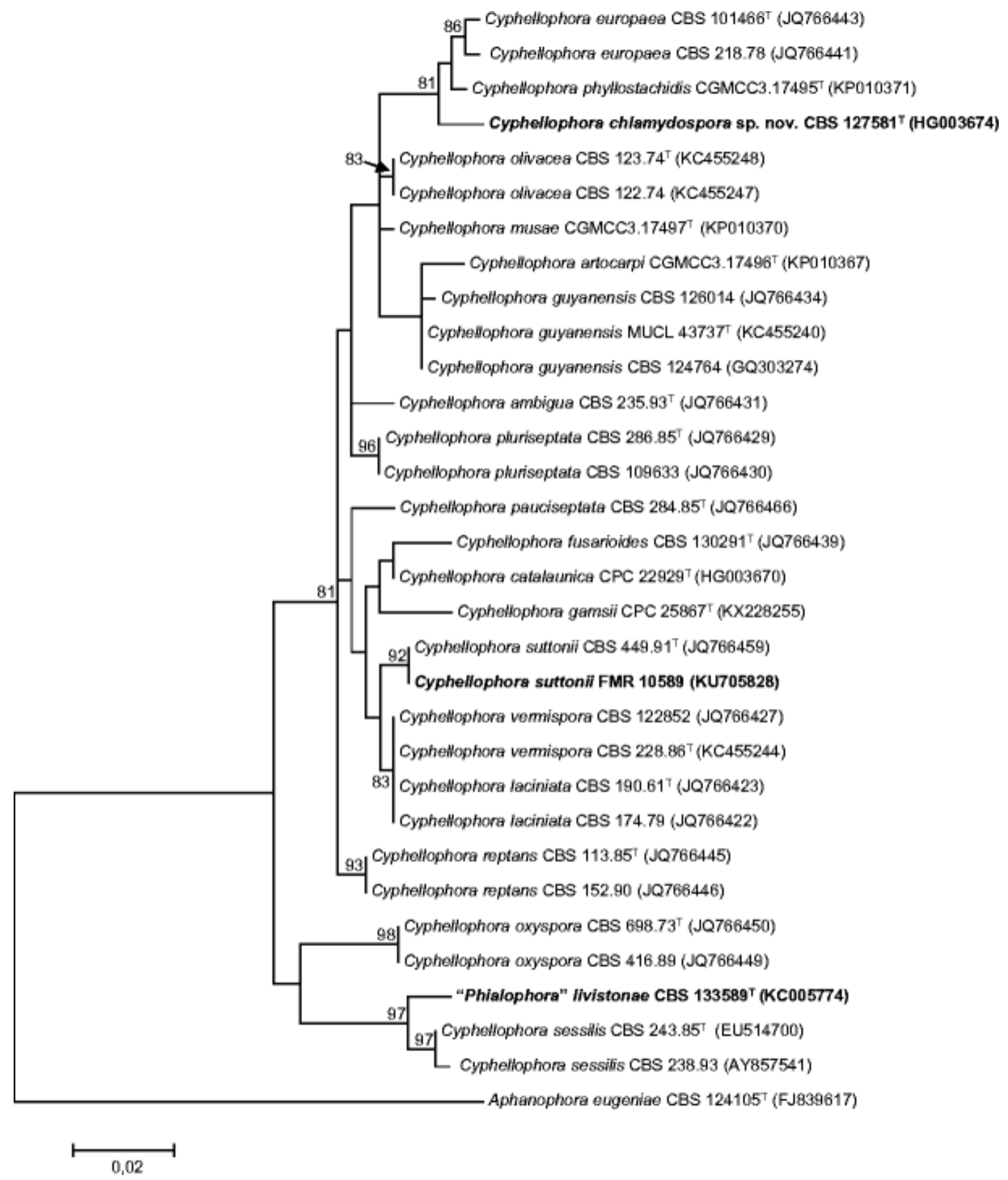

Fig. 3. Maximum likelihood tree constructed with partial sequences of the ITS region of Cyphellophora spp. Branch lengths are proportional to distance. Bootstrap values $\geq 70 \%$ are shown near the internodes. The ingroup includes all species of this genus for which DNA sequences are available at GenBank. Aphanophora eugeniae was used as outgroup. ${ }^{\top}$ ex-type strain 


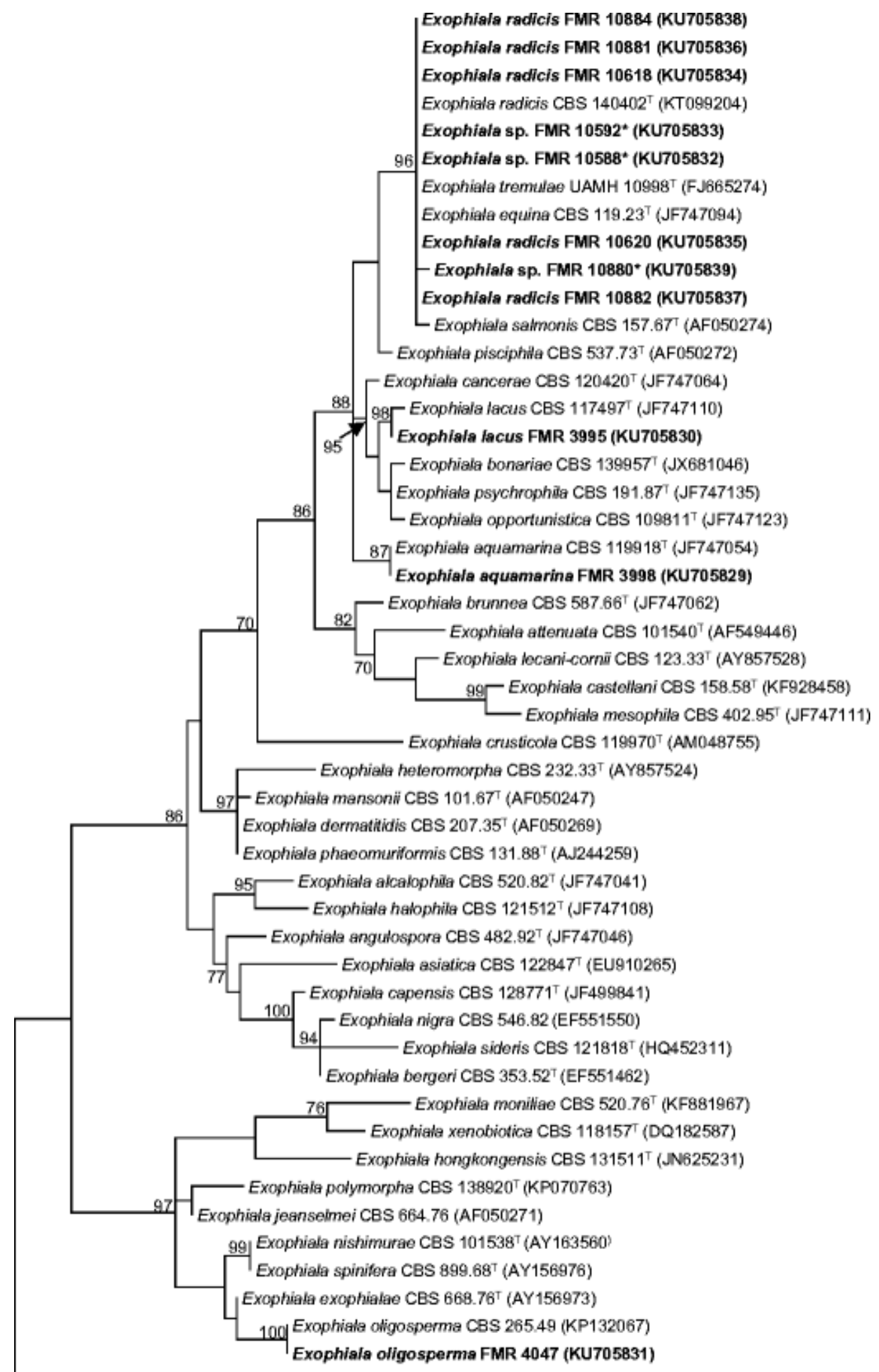

Exophiala placitae CBS $121716^{\top}$ (EU040215)

\section{0,02}

Fig. 4. Maximum likelihood tree constructed with partial sequences of the ITS region of Exophiala spp. Branch lengths are proportional to distance. Bootstrap values $\geq 70 \%$ are shown near the internodes. The ingroup includes all species of this genus belonging to Herpotrichiellaceae for which DNA sequences are available at GenBank. Exophiala placitae, a species related to Trichomeriaceae (Réblová et al. 2013; Gueidan et al. 2014), was used as outgroup. ' ex-type strain; * Exophiala strains requiring data from additional loci for a definitive species-level identification 


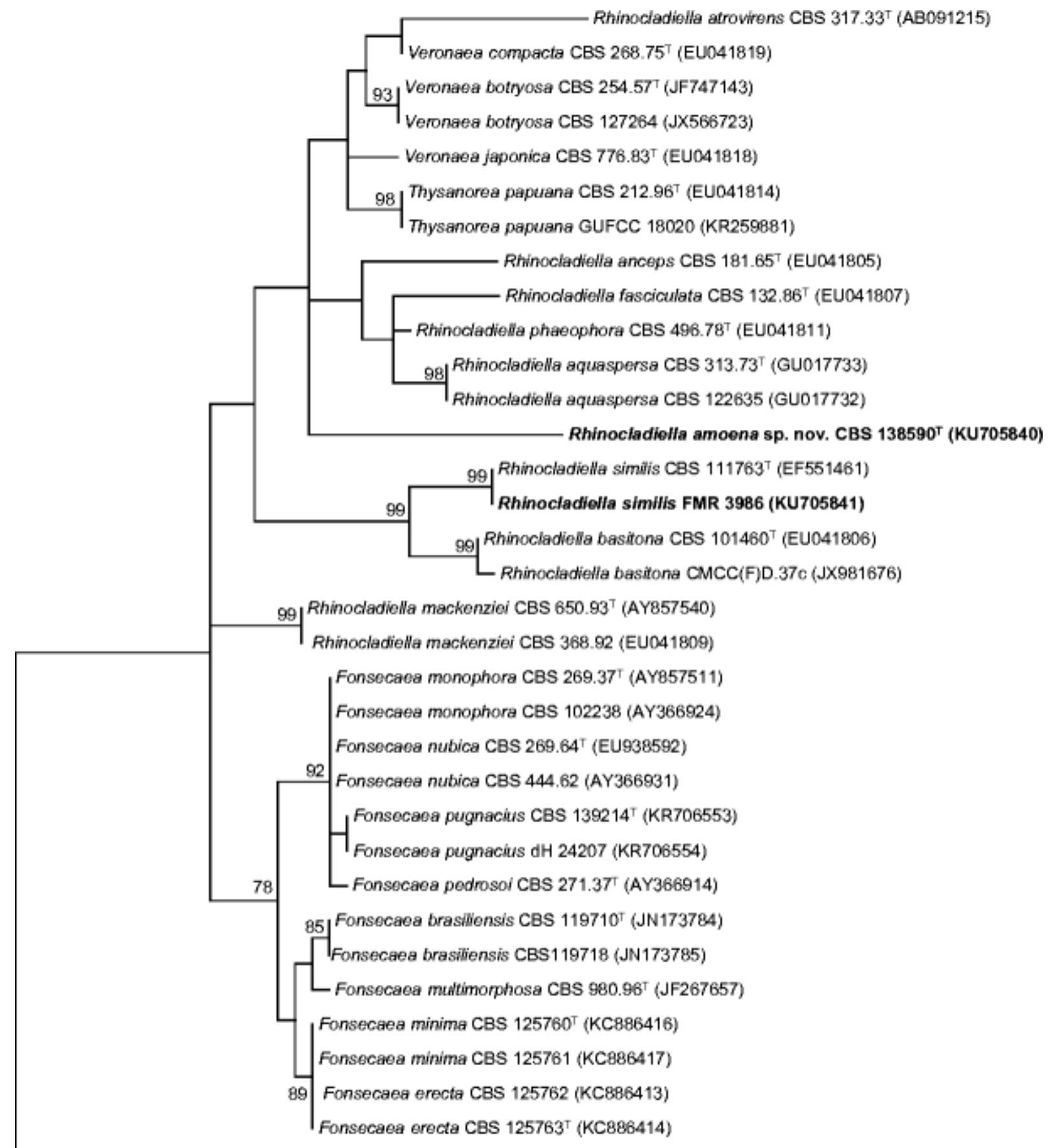

Endocarpon pusiñum CG470 (JQ927447)

0.02

Fig. 5. Maximum likelihood tree constructed with partial sequences of the ITS region of Rhinocladiella spp. and morphologically similar genera in Chaetothyriales. Branch lengths are proportional to distance. Bootstrap values $\geq 70 \%$ are shown near the internodes. The ingroup includes all species of this genus for which DNA sequences are available at GenBank. Endocarpon pusillum (Verrucariaceae, Gueidan et al. 2014) was used as outgroup. ${ }^{\top}$ ex-type strain 
Table 1. Strains included in the phylogenetic studies, their origins and EMBL accession no. ( ${ }^{\top}$ ex-type strain)

\begin{tabular}{|c|c|c|c|c|c|c|}
\hline \multirow{2}{*}{ Taxon } & \multirow{2}{*}{ Isolate no. } & \multirow{2}{*}{ Substrate } & \multirow{2}{*}{ Geographical origin } & \multicolumn{2}{|c|}{ EMBL accession \# } & \multirow{2}{*}{ References } \\
\hline & & & & ITS & LSU & \\
\hline $\begin{array}{l}\text { Ant-associated unidentified } \\
\text { Chaetothyriales }\end{array}$ & T221_Tm15 & $\begin{array}{l}\text { Azteca brevis Forel ant } \\
\text { carton }\end{array}$ & Costa Rica & & KF614892 & $\begin{array}{l}\text { Nepel et al. } \\
\text { (2014) }\end{array}$ \\
\hline $\begin{array}{l}\text { Ant-associated unidentified } \\
\text { Chaetothyriales }\end{array}$ & T223_Tm14 & $\begin{array}{l}\text { Azteca brevis Forel ant } \\
\text { carton }\end{array}$ & Costa Rica & & KF614884 & $\begin{array}{l}\text { Nepel et al. } \\
(2014)\end{array}$ \\
\hline $\begin{array}{l}\text { Ant-associated unidentified } \\
\text { Chaetothyriales }\end{array}$ & T230_Tm1 & $\begin{array}{l}\text { Azteca brevis Forel ant } \\
\text { carton }\end{array}$ & Costa Rica & & KF614885 & $\begin{array}{l}\text { Nepel et al. } \\
(2014)\end{array}$ \\
\hline $\begin{array}{l}\text { Aphanophora eugeniae } \\
\text { (Crous \& Alfenas) Réblová \& } \\
\text { Unter. }\end{array}$ & CBS $124105^{\top}$ & $\begin{array}{l}\text { Living leaves of Eugenia } \\
\text { uniflora } \mathrm{L} \text {. }\end{array}$ & $\begin{array}{l}\text { Guaiba, Rio Grande } \\
\text { do Sul, Brazil }\end{array}$ & FJ839617 & FJ839652 & $\begin{array}{l}\text { Crous et al. } \\
(2009)\end{array}$ \\
\hline $\begin{array}{l}\text { Camptophora hylomeconis } \\
\text { (Crous, de Hoog \& H.D. Shin) } \\
\text { Réblová \& Unter. }\end{array}$ & CBS $113311^{\top}$ & $\begin{array}{l}\text { Leaves of Hylomecon } \\
\text { vernalis Maxim. }\end{array}$ & $\begin{array}{l}\text { Yangpyeong, } \\
\text { Gyeonggi, South } \\
\text { Korea }\end{array}$ & & EU035415 & $\begin{array}{l}\text { Crous et al. } \\
\text { (2007b) }\end{array}$ \\
\hline \multicolumn{7}{|l|}{ Chaetothyriales sp. } \\
\hline $\begin{array}{l}\text { (= Cyphellophora } \\
\text { chlamydospora Madrid, } \\
\text { Hern.-Restr., Cano, Gené, } \\
\text { Guarro \& V. Silva, sp. nov.) }\end{array}$ & (= FMR 10878) & Soil & $\begin{array}{l}\text { Castellvell del Camp, } \\
\text { Tarragona, Spain }\end{array}$ & HG003674 & HG003675 & This study \\
\hline $\begin{array}{l}\text { Chaetothyrium agathis } \\
\text { Hongsanan \& K.D. Hyde }\end{array}$ & $\begin{array}{l}\text { MFLUCC } 12 \\
\text { C0113 }\end{array}$ & Leaf of Agathis sp. & $\begin{array}{l}\text { Mount Makiling, } \\
\text { Laguna, Phillippines }\end{array}$ & & KP744480 & Liu et al. (2015) \\
\hline $\begin{array}{l}\text { Cladophialophora abundans } \\
\text { P. Feng, V.A. Vicente, M.J. } \\
\text { Najafz., A.H.G. Gerrits van }\end{array}$ & CBS $126736^{\top}$ & $\begin{array}{l}\text { Thorn of Smilax } \\
\text { campestris Griseb. }\end{array}$ & $\begin{array}{l}\text { Bacabeira, Maranhão, } \\
\text { Brazil }\end{array}$ & KC776592 & KC812100 & $\begin{array}{l}\text { Feng et al. } \\
\text { (2014) }\end{array}$ \\
\hline $\begin{array}{l}\text { den Ende, B. Stielow, H. } \\
\text { Badali, W.A. Boeger \& de } \\
\text { Hoog }\end{array}$ & CBS 127907 & $\begin{array}{l}\text { Soil from mangrove } \\
\text { environment }\end{array}$ & Acupi, Bahia, Brazil & KC776597 & & $\begin{array}{l}\text { Feng et al. } \\
\text { (2014) }\end{array}$ \\
\hline $\begin{array}{l}\text { Cladophialophora arxii } \\
\text { Tintelnot }\end{array}$ & CBS $306.94^{\top}$ & Tracheal abscess, human & Germany & EU103986 & & $\begin{array}{l}\text { Badali et al. } \\
\text { (2009) }\end{array}$ \\
\hline $\begin{array}{l}\text { Cladophialophora } \\
\text { australiensis Crous \& A.D. } \\
\text { Hocking }\end{array}$ & CBS $112793^{\top}$ & Sports drink & Australia & EU035402 & & $\begin{array}{l}\text { Crous et al. } \\
(2007 a, b)\end{array}$ \\
\hline \multirow{3}{*}{$\begin{array}{l}\text { Cladophialophora bantiana } \\
\text { (Sacc.) de Hoog, Kwon-Chung } \\
\text { \& McGinnis }\end{array}$} & CBS 173.52 & Brain abscess, human & USA & EU103989 & & $\begin{array}{l}\text { Badali et al. } \\
\text { (2009) }\end{array}$ \\
\hline & CBS 648.96 & Liver of a dog & Barbados & EU103993 & & $\begin{array}{l}\text { Badali et al. } \\
\text { (2009) }\end{array}$ \\
\hline & & & & & & $\begin{array}{l}\text { ITS: Badali et al. } \\
\text { (2009), }\end{array}$ \\
\hline \multirow[t]{3}{*}{$\begin{array}{l}\text { Cladophialophora boppii } \\
\text { (Borelli) de Hoog, Kwon- } \\
\text { Chung \& McGinnis }\end{array}$} & CBS $126.86^{\top}$ & Skin lesion, human & Brazil & EU103997 & FJ358233 & $\begin{array}{l}\text { LSU: Gueidan et } \\
\text { al. (2008) }\end{array}$ \\
\hline & CBS 110029 & Facial skin, human & $\begin{array}{l}\text { Dordrecht, } \\
\text { Netherlands }\end{array}$ & EU103998 & & $\begin{array}{l}\text { Badali et al. } \\
\text { (2009) }\end{array}$ \\
\hline & & & & & & $\begin{array}{l}\text { ITS: Abliz et al. } \\
\text { (2004a) }\end{array}$ \\
\hline \multirow[t]{3}{*}{$\begin{array}{l}\text { Cladophialophora carrionii } \\
\text { (Trejos) de Hoog, Kwon- } \\
\text { Chung \& McGinnis }\end{array}$} & CBS $160.54^{\top}$ & $\begin{array}{l}\text { Chromoblastomycosis, } \\
\text { human }\end{array}$ & Australia & AB109177 & FJ358234 & $\begin{array}{l}\text { LSU: Gueidan et } \\
\text { al. (2008) }\end{array}$ \\
\hline & CBS 114393 & $\begin{array}{l}\text { Chromoblastomycosis, } \\
\text { human }\end{array}$ & $\begin{array}{l}\text { Falcón State, } \\
\text { Venezuela }\end{array}$ & KF928452 & & $\begin{array}{l}\text { Attili-Angelis et } \\
\text { al. (2014) }\end{array}$ \\
\hline & CBS 491.70 & $\begin{array}{l}\text { Roots of Picea abies (L.) } \\
\text { Karst. }\end{array}$ & Denmark & & EU035405 & $\begin{array}{l}\text { Crous et al. } \\
(2007 a, b)\end{array}$ \\
\hline \multirow[t]{2}{*}{$\begin{array}{l}\text { Cladophialophora } \\
\text { chaetospira (Grove) Crous \& } \\
\text { Arzanlou }\end{array}$} & CBS 114747 & Decaying bamboo & Yunnan, Jiliang, China & EU035403 & & $\begin{array}{l}\text { Crous et al. } \\
(2007 a, b)\end{array}$ \\
\hline & CBS 115468 & Bamboo wood & Yunnan, Jiliang, China & EU035404 & & $\begin{array}{l}\text { Crous et al. } \\
(2007 a, b)\end{array}$ \\
\hline $\begin{array}{l}\text { Cladophialophora devriesii } \\
\text { (A.A. Padhye \& Ajello) de } \\
\text { Hoog, Kwon-Chung \& }\end{array}$ & CBS $147.84^{\top}$ & $\begin{array}{l}\text { Granulomatous lesion, } \\
\text { human }\end{array}$ & Grand Cayman Island & EU103985 & & $\begin{array}{l}\text { Badali et al. } \\
\text { (2009) }\end{array}$ \\
\hline
\end{tabular}


Isolate no.

Cladophialophora emmonsii (A.A. Padhye, McGinnis \& Ajello) de Hoog \& A.A.

Padhye

CBS $979.96^{\top}$

CBS 640.96

Cladophialophora floridana

Obase, Douhan, Y. Matsuda, ATCC TSD $-8^{\top}$

\& M.E.Sm.

Cladophialophora immunda Badali, M.M. Satow, Prenaf.-

Boldú, \& de Hoog

CBS $834.96^{\top}$

CBS 110551

Cladophialophorea

matsushimae Koukol

MFC-1P384

Cladophialophora minourae (Iwatsu) Haase \& de Hoog

Cladophialophora

multiseptata Madrid, Cano,

Najafz., de Hoog, C. Silvera \&

Crous

Cladophialophora

mycetomatis Badali, de Hoog

\& Bonifaz

Cladophialophora parmeliae

(Etayo \& Diederich) Diederich

\& Untereiner

CBS 129337

Cladophialophora

potulentorum Crous \& A.D. Hocking

Cladophialophora

psammophila Badali,

Prenafeta-Boldú, Guarro \&

de Hoog

Cladophialophora

pucciniophila M.J. Park \& KACC $43957^{\top}$

H.D. Shin

Cladophialophora samöensis

Badali, de Hoog \& Padhye

CBS $259.83^{\top}$

human

Substrate

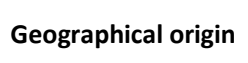

EMBL

Subcutaneous lesion,

Virginia state, USA

EU103996

Badali et al.

(2009)

Subcutaneous lesion, cat Unknown

EU103995

Badali et al.

(2009)

Sclerotium of

Cenococcum geophilum Gainesville, Florida,

Fr.

USA

Obase et al.

(2016)

Subcutaneous ulcer, human

Atlanta, Georgia, USA EU137318

De Hoog et al.

(2007)

Prenafeta-Boldú

Apeldoorn,

AY857510

et al. (2006)

Decaying petioles of palm tree

Decaying wood

Momón River, Peru

FN549916 FN400758 Koukol (2010)

Shiroi, Chiba, Japan AY251087

Braun et al.

(2003)

Carrascal de la Font

Roja Natural Park, HG003668 HG003671 Crous et al. Alicante, Spain

(2013)

Soil

CBS 122637

Mycetoma, human

Jicaltepec, Mexico

FJ385276

Badali et al.

(2008)

Culture contaminant Netherlands

Hypotrachyna sp. Azores

Hypotrachyna
imbricatula (Zahlbr.) Hale Azores

Apple juice drink

Australia

(x)

Feng et al.

(2014)

JX081671 Lawrey et al.

(2013)

Lawrey et al.

(2013)

Crous et al.

(2007a, b)

CBS $110553^{\top}$

Gasolin-polluted soil

Bennekom,

Netherlands

AY857517

Prenafeta-Boldú

et al. (2006)

Rust telia of Puccinia Bongmyeong-ri, polygoni-amphibii Pers. Gangwon, Korea

JF263534 Park and Shin (2011)

ITS: de Hoog et al. (2007),

EU137291 KC809992

LSU: Feng et al. (2014)

Interdigital skin lesion, Curitiba, Paraná, human Brazil

Badali et al. (2009)

Leaf lesions of Scilla peruviana $\mathrm{L}$.

Manurewa, Auckland, New Zealand

Crous et al. (2007a, b)

(Deighton) Crous, U. Braun \& CBS 116461 K. Schub.

Cladophialophora sp.

(= Cladophialophora pseudocarrionii Madrid, Hern.-Restr., Gené, Cano \& Guarro, sp. nov.)

Cladophialophora subtilis Badali \& de Hoog

CBS 138591

Soil

(= FMR 12062) Soil

CBS $122642^{\top} \quad$ Ice tea

Sclerotium of

Cladophialophora tortuosa

Obase, Douhan, Y. Matsuda, ATCC TSD $-9^{\top}$

\& M.E.Sm.
Cenococcum geophilum Fr.
Hayedo de la Tejera

Negra National Park, KU705827 KU705844 This study Guadalajara, Spain

Utrecht, Netherlands FJ385273 Badali et al.

(2008)

Gainesville, Florida, AB986424 AB986424 Obase et al. USA

(2016) 


\begin{tabular}{|c|c|c|c|c|c|c|}
\hline \multirow{5}{*}{$\begin{array}{l}\text { Taxon } \\
\text { Cladophialophora yegresii de } \\
\text { Hoog, Nishikaku, } \\
\text { Zeppenfeldt, Ruibal \& Gerrits } \\
\text { van den Ende }\end{array}$} & \multirow{3}{*}{ Isolate no. } & \multirow{3}{*}{ Substrate } & \multirow{3}{*}{ Geographical origin } & \multicolumn{2}{|c|}{ EMBL accession \# } & \multirow{2}{*}{ References } \\
\hline & & & & ITS & LSU & \\
\hline & & & & & & $\begin{array}{l}\text { ITS: de Hoog et } \\
\text { al. (2007) }\end{array}$ \\
\hline & CBS $114405^{\top}$ & $\begin{array}{l}\text { Stenocereus griseus } \\
\text { (Haw.) Buxb. }\end{array}$ & $\begin{array}{l}\text { Falcón State, } \\
\text { Venezuela }\end{array}$ & EU137322 & KC809994 & $\begin{array}{l}\text { LSU: Feng et al. } \\
\text { (2014) }\end{array}$ \\
\hline & CBS 114407 & $\begin{array}{l}\text { Stenocereus griseus } \\
\text { (Haw.) Buxb. }\end{array}$ & $\begin{array}{l}\text { Falcón State, } \\
\text { Venezuela }\end{array}$ & EU137324 & & $\begin{array}{l}\text { de Hoog et al. } \\
\text { (2007) }\end{array}$ \\
\hline $\begin{array}{l}\text { Cyphellophora ambigua (P. } \\
\text { Feng \& de Hoog) Réblová \& } \\
\text { Unter. }\end{array}$ & CBS $235.93^{\top}$ & Human toe nail & Delft, Netherlands & JQ766431 & JQ766480 & $\begin{array}{l}\text { Feng et al. } \\
\text { (2012) }\end{array}$ \\
\hline $\begin{array}{l}\text { Cyphellophora artocarpi G.Y. } \\
\text { Sun \& Liu Gao }\end{array}$ & CGMCC3.17496 ${ }^{\top}$ & $\begin{array}{l}\text { Twig of Artocarpus } \\
\text { heterophyllus Lam. }\end{array}$ & Haikou, Hainan, China & КР010367 & KP122930 & Gao et al. (2015) \\
\hline $\begin{array}{l}\text { Cyphellophora catalaunica } \\
\text { Madrid, Gené, Guarro \& } \\
\text { Crous }\end{array}$ & CPC $22929^{\top}$ & River sediments & $\begin{array}{l}\text { Pals beach, Girona, } \\
\text { Spain }\end{array}$ & HG003670 & HG003673 & $\begin{array}{l}\text { Crous et al. } \\
(2013)\end{array}$ \\
\hline \multirow{4}{*}{$\begin{array}{l}\text { Cyphellophora europaea (de } \\
\text { Hoog, Mayser \& Haase) } \\
\text { Réblová \& Unter. }\end{array}$} & & & & & & $\begin{array}{l}\text { ITS: Feng et al. } \\
\text { (2012) }\end{array}$ \\
\hline & CBS $101466^{\top}$ & Foot of human patient & $\begin{array}{l}\text { Dordrecht, } \\
\text { Netherlands }\end{array}$ & JQ766443 & KC455259 & \\
\hline & & & & & & $\begin{array}{l}\text { LSU: Réblová et } \\
\text { al. (2013) }\end{array}$ \\
\hline & CBS 218.78 & Finger nail & $\begin{array}{l}\text { Rotterdam, } \\
\text { Netherlands }\end{array}$ & JQ766441 & & $\begin{array}{l}\text { Feng et al. } \\
(2012)\end{array}$ \\
\hline \multirow{3}{*}{$\begin{array}{l}\text { Cyphellophora fusarioides (B. } \\
\text { Sutton \& C.K. Campb.) } \\
\text { Decock }\end{array}$} & & & & & & $\begin{array}{l}\text { ITS: Feng et al. } \\
\text { (2012) }\end{array}$ \\
\hline & CBS $130291^{\top}$ & $\begin{array}{l}\text { Human bronchial lavage } \\
\text { fluid }\end{array}$ & Israel & JQ766439 & KC455252 & \\
\hline & & & & & & $\begin{array}{l}\text { LSU: Réblová et } \\
\text { al. (2013) }\end{array}$ \\
\hline \multirow[t]{2}{*}{ Cyphellophora gamsii Crous } & CPC $25867^{\top}$ & Leaf litter & Chiang Mai, Thailand & KX228255 & KX228307 & $\begin{array}{l}\text { Crous et al. } \\
(2016)\end{array}$ \\
\hline & CBS 124764 & Eucalyptus sp. & Australia & GQ303274 & & $\begin{array}{l}\text { Cheewangkoon } \\
\text { et al. (2009) }\end{array}$ \\
\hline \multirow{3}{*}{$\begin{array}{l}\text { Cyphellophora guyanensis } \\
\text { Decock \& G. Delgado }\end{array}$} & CBS 126014 & Tucum palm & Brazil & JQ766434 & & $\begin{array}{l}\text { Feng et al. } \\
\text { (2012) }\end{array}$ \\
\hline & MUCL $43737^{\top}$ & $\begin{array}{l}\text { Dead leaf of } \\
\text { undetermined } \\
\text { angiosperm }\end{array}$ & $\begin{array}{l}\text { Matouri, Cayenne } \\
\text { area, French Guyana }\end{array}$ & KC455240 & KC455253 & $\begin{array}{l}\text { Réblová et al. } \\
\text { (2013) }\end{array}$ \\
\hline & CBS 174.79 & Foot skin, human & Unknown & JQ766422 & & $\begin{array}{l}\text { Feng et al. } \\
(2012)\end{array}$ \\
\hline \multirow{3}{*}{$\begin{array}{l}\text { Cyphellophora laciniata G.A. } \\
\text { de Vries }\end{array}$} & & & & & & $\begin{array}{l}\text { ITS: Feng et al. } \\
\text { (2012) }\end{array}$ \\
\hline & CBS $190.61^{\top}$ & Skin, human & Basel, Switzerland & JQ766423 & FJ358239 & \\
\hline & & & & & & $\begin{array}{l}\text { LSU: Gueidan et } \\
\text { al. (2008) }\end{array}$ \\
\hline $\begin{array}{l}\text { Cyphellophora musae G.Y. } \\
\text { Sun \& Liu Gao }\end{array}$ & CGMCC3.17497 & $\begin{array}{l}\text { Fruit of Musa basjoo } \\
\text { Siebold \& Zucc. ex } \\
\text { Linuma }\end{array}$ & $\begin{array}{l}\text { Zhanjiang, } \\
\text { Guangdong, China }\end{array}$ & KP010370 & KP122932 & Gao et al. (2015) \\
\hline \multirow{3}{*}{$\begin{array}{l}\text { Cyphellophora olivacea (W. } \\
\text { Gams) Réblová \& Unter. }\end{array}$} & CBS 122.74 & Moist wall paper & $\begin{array}{l}\text { Kiel-Kitzeberg, } \\
\text { Germany }\end{array}$ & KC455247 & KC455260 & $\begin{array}{l}\text { Réblová et al. } \\
\text { (2013) }\end{array}$ \\
\hline & CBS $123.74^{\top}$ & $\begin{array}{l}\text { Stem of Chamaerops } \\
\text { humilis L. }\end{array}$ & Baarn, Netherlands & KC455248 & & $\begin{array}{l}\text { Réblová et al. } \\
\text { (2013) }\end{array}$ \\
\hline & CBS 416.89 & Floor of swimming pool & Germany & JQ766449 & & $\begin{array}{l}\text { Feng et al. } \\
\text { (2012) }\end{array}$ \\
\hline \multirow[t]{3}{*}{$\begin{array}{l}\text { Cyphellophora oxyspora (W. } \\
\text { Gams) Réblová \& Unter. }\end{array}$} & & & & & & $\begin{array}{l}\text { ITS: Feng et al. } \\
(2012)\end{array}$ \\
\hline & CBS $698.73^{\top}$ & $\begin{array}{l}\text { Clerodendron sp., } \\
\text { decaying leaf }\end{array}$ & $\begin{array}{l}\text { Peradeniya Botanical } \\
\text { Garden, Sri Lanka }\end{array}$ & JQ766450 & KC455262 & \\
\hline & & & & & & $\begin{array}{l}\text { LSU: Réblová et } \\
\text { al. (2013) }\end{array}$ \\
\hline $\begin{array}{l}\text { Cyphellophora pauciseptata } \\
\text { P. Feng \& de Hoog }\end{array}$ & CBS $284.85^{\top}$ & Skin of hand, human & $\begin{array}{l}\text { Roermond, Limburg, } \\
\text { Netherlands }\end{array}$ & JQ766466 & JQ766515 & $\begin{array}{l}\text { Feng et al. } \\
\text { (2012) }\end{array}$ \\
\hline Cyphellophora phyllostachidis & CGMCC3.17495 & Twig of Phyllostachys sp. & Haikou, Hainan, China & КР010371 & KP122933 & Gao et al. (2015) \\
\hline
\end{tabular}


Cyphellophora pluriseptata G.A. de Vries, Elders \& Luykx

Cyphellophora reptans de
Hoog
Cyphellophora sessilis (de
Hoog) Réblová \& Unter.

Cyphellophora suttonii (Ajello, A.A. Padhye \& M Payne) Decock

\begin{tabular}{|c|c|c|c|c|c|c|}
\hline & FMR 10589 & Soil & $\begin{array}{l}\text { Tarragona, } \\
\text { Tarragona, Spain }\end{array}$ & KU705828 & KU705845 & This study \\
\hline \multirow{2}{*}{$\begin{array}{l}\text { Cyphellophora vermispora A. } \\
\text { Walz \& de Hoog }\end{array}$} & CBS $228.86^{\top}$ & $\begin{array}{l}\text { Root of Tritichum } \\
\text { aestivum L. }\end{array}$ & Monheim, Germany & KC455244 & KC455257 & $\begin{array}{l}\text { Réblová et al. } \\
\text { (2013) }\end{array}$ \\
\hline & CBS 122852 & Skin of foot, human & Netherlands & JQ766427 & & $\begin{array}{l}\text { Feng et al. } \\
(2012)\end{array}$ \\
\hline Endocarpon pusillum Hedw. & CG470 & Unknown & Unknown & JQ927447 & & $\begin{array}{l}\text { Weerakoon et al. } \\
(2012)\end{array}$ \\
\hline $\begin{array}{l}\text { Exophiala alcalophila Goto } \\
\text { \&Sujiy. }\end{array}$ & CBS $520.82^{\top}$ & Soil & $\begin{array}{l}\text { Wako-shi, Saitama, } \\
\text { Japan }\end{array}$ & JF747041 & & $\begin{array}{l}\text { de Hoog et al. } \\
\text { (2011) }\end{array}$ \\
\hline $\begin{array}{l}\text { Exophiala angulospora } \\
\text { Iwatsu, Udagawa \& T. Takase }\end{array}$ & CBS $482.92^{\top}$ & Water from drinking well & $\begin{array}{l}\text { Yokohama-shi, } \\
\text { Kanagawa, Japan }\end{array}$ & JF747046 & & $\begin{array}{l}\text { de Hoog et al. } \\
\text { (2011) }\end{array}$ \\
\hline \multirow{2}{*}{$\begin{array}{l}\text { Exophiala aquamarina de } \\
\text { Hoog, Vicente, Najafz., } \\
\text { Harrak, Badali, Seyedm. \& } \\
\text { Nyaoke }\end{array}$} & CBS $119918^{\top}$ & Leafy seadragon, skin & $\begin{array}{l}\text { Boston, } \\
\text { Massachusetts, USA }\end{array}$ & JF747054 & & $\begin{array}{l}\text { de Hoog et al. } \\
\text { (2011) }\end{array}$ \\
\hline & FMR 3998 & River sediments & $\begin{array}{l}\text { Ebro River mouth, } \\
\text { Riumar beach, } \\
\text { Tarragona, Spain }\end{array}$ & KU705829 & KU705846 & This study \\
\hline $\begin{array}{l}\text { Exophiala asiatica D.M. Li, } \\
\text { R.Y. Li, de Hoog \& D.L. Wang }\end{array}$ & CBS $122847^{\top}$ & $\begin{array}{l}\text { Wound infection of } \\
\text { tonsils, human }\end{array}$ & China & EU910265 & & Li et al. (2011) \\
\hline $\begin{array}{l}\text { Exophiala attenuata Vitale \& } \\
\text { de Hoog }\end{array}$ & CBS $101540^{\top}$ & Soil & Colombia & AF549446 & & $\begin{array}{l}\text { Vitale and de } \\
\text { Hoog (2002) }\end{array}$ \\
\hline $\begin{array}{l}\text { Exophiala bergeri Haase \& de } \\
\text { Hoog }\end{array}$ & CBS $353.52^{\top}$ & Skin infection, human & Canada & EF551462 & & $\begin{array}{l}\text { Zeng and de } \\
\text { Hoog (2008) }\end{array}$ \\
\hline $\begin{array}{l}\text { Exophiala bonariae D. isola \& } \\
\text { L. Zucconi }\end{array}$ & CBS $139957^{\top}$ & $\begin{array}{l}\text { Surface of marble } \\
\text { funerary monument }\end{array}$ & Cagliari, Sardinia, Italy & JX681046 & & Isola et al. (2013) \\
\hline Exophiala brunnea Papendorf & CBS $587.66^{\top}$ & $\begin{array}{l}\text { Leaf litter of Acacia } \\
\text { karroo Hayne }\end{array}$ & $\begin{array}{l}\text { Potchefstroom, North } \\
\text { West Province, South } \\
\text { Africa }\end{array}$ & $J F 747062$ & & $\begin{array}{l}\text { de Hoog et al. } \\
\text { (2011) }\end{array}$ \\
\hline $\begin{array}{l}\text { Exophiala cancerae de Hoog, } \\
\text { V.A. Vicente, Najafz., Harrak, } \\
\text { Badali, Seyedm. \& Boeger }\end{array}$ & CBS $120420^{\top}$ & $\begin{array}{l}\text { Diseased mangrove crab } \\
\text { (Ucides cordatus L.) }\end{array}$ & $\begin{array}{l}\text { Goiana City, } \\
\text { Pernambuco, Brazil }\end{array}$ & JF747064 & & $\begin{array}{l}\text { de Hoog et al. } \\
\text { (2011) }\end{array}$ \\
\hline Exophiala capensis Crous & CBS $128771^{\top}$ & $\begin{array}{l}\text { Leaf of Phaenocoma } \\
\text { prolifera (L.) D. Don }\end{array}$ & $\begin{array}{l}\text { Fernkloof Nature } \\
\text { Reserve, Western } \\
\text { Cape Province, South } \\
\text { Africa }\end{array}$ & JF499841 & & $\begin{array}{l}\text { Crous and } \\
\text { Groenewald } \\
(2011)\end{array}$ \\
\hline $\begin{array}{l}\text { Exophiala castellani Iwatsu, } \\
\text { Nishim. \& Miyaji }\end{array}$ & CBS $158.58^{\top}$ & Human & Sri Lanka & KF928458 & & $\begin{array}{l}\text { Attili-Angelis et } \\
\text { al. (2014) }\end{array}$ \\
\hline $\begin{array}{l}\text { Exophiala crusticola S.T. } \\
\text { Bates, G.S.N. Reddy \& García- }\end{array}$ & CBS $119970^{\top}$ & Biological soil crust & $\begin{array}{l}\text { Colorado Plateau, } \\
\text { USA }\end{array}$ & AM048755 & & $\begin{array}{l}\text { Bates et al. } \\
(2006)\end{array}$ \\
\hline
\end{tabular}

ITS: Feng et al. (2012)

$\begin{array}{lll}\text { CBS } 286.85^{\top} & \begin{array}{l}\text { Foot skin of human } \\ \text { patient }\end{array} & \begin{array}{l}\text { Roermond, } \\ \text { Netherlands }\end{array}\end{array}$

JQ766429 KC455255

LSU: Réblová et al. (2013)

Feng et al. (2012)

Feng et al. (2012)

Feng et al. (2012) Prenafeta-Boldú

AY857541 $\quad$ et al. (2006)

EU514700 EU514700 Untereiner et al. ITS: Feng et al. (2012),

JQ766459 KC455256

LSU: Réblová et al. (2013)

Subcutaneous tissue of a USA

$\begin{array}{lcl}\begin{array}{l}\text { Noord-Holland, } \\ \text { Netherlands }\end{array} & \text { JQ766446 } & \begin{array}{l}\text { Feng et al. } \\ \text { (2012) }\end{array} \\ \text { Delft. Netherlands } & \text { AY857541 } & \begin{array}{l}\text { Prenafeta-Boldú } \\ \text { et al. (2006) }\end{array} \\ \text { Baarn, Netherlands } \quad \text { EU514700 EU514700 } & \begin{array}{l}\text { Untereiner et al. } \\ (2008)\end{array} \\ & & \begin{array}{l}\text { ITS: Feng et al. } \\ (2012),\end{array}\end{array}$

$\begin{array}{lll}\text { CBS 109633 } & \text { Human skin } & \text { Giessen, Germany } \\ \text { CBS 113.85 } & \text { Food stuffs } & \text { Uppsala, Sweden } \\ \text { CBS 152.90 } & \text { Toe nail, human } & \begin{array}{l}\text { Noord-Holland, } \\ \text { Netherlands }\end{array} \\ \text { CBS 238.93 } & \begin{array}{l}\text { Biological filter for } \\ \text { styrene-containing fumes }\end{array} & \text { Delft. Netherlands } \\ \text { CBS 243.85 } & \begin{array}{l}\text { Resin of Picea abies (L.) } \\ \text { H. Karst. }\end{array} & \text { Baarn, Netherlands } \\ & & \\ \text { CBS 449.91 } & \begin{array}{l}\text { Subcutaneous tissue of a } \\ \text { dog }\end{array} & \text { USA }\end{array}$

Tarragona,

Tarragona, Spain

Réblová et al.

Feng et al.

(2012)

(2011)

de Hoog et al.

de Hoog et al.

(2011)

Ebro River mouth,

mar beach,

Tarragona, Spain

China

Vitale and de

Hoog (2002)

Zeng and de

de Hoog et al

de Hoog et al.

Crous and

Groenewald

Attili-Angelis et

Bates et al. 
Pichel

Exophiala dermatitidis (Kano) de Hoog
Human

CBS $119.23^{\top}$

Exophiala equina (Pollacci) de Hoog, V.A. Vicente, Najafz., CBS 160.89 Harrak, Badali \& Seyedm.

CBS 116009

Exophiala exophialae (de Hoog) de Hoog

CBS $668.76^{\top}$

Exophiala halophila de Hoog,

V.A. Vicente, Najafz., Harrak, CBS $121512^{\top}$ Badali \& Seyedm.

Exophiala heteromorpha (Nannf.) de Hoog \& Haase

CBS $232.33^{\top}$

Exophiala hongkongensis P.C.

Woo, A.H. Ngan, C.C. Tsang,

I.W. Ling, J.F. Chan, S.Y.

Leung, K.Y. Yuen \& S.K. Lau

Exophiala jeanselmei

(Langeron) McGinnis \& A.A. C CBS 664.76

Padhye

Exophiala lacus de Hoog, V.A.
Vicente, Najafz., Harrak,

CBS $117497^{\top} \quad$ Lake water

Badali \& Seyedm.

FMR 3995

Exophiala lecani-cornii

(Benedek \& G. Specht) Haase CBS $123.33^{\top}$

$\&$ de Hoog

Exophiala mansonii (Castell.) de Hoog

Exophiala mesophila

Listeman \& Freiesl.

Exophiala moniliae de Hoog

Exophiala nigra (Issatsch.)

Haase \& de Hoog

Exophiala nishimurae Vitale

\& de Hoog

Exophiala opportunistica de Hoog, V.A. Vicente, Najafz., Harrak, Badali \& Seyedm.

Exophiala oligosperma Calendron ex de Hoog \& Tintelnot (Matsumoto, A.A. Padhye, Ajello \& McGinnis) Matos, Haase \& de Hoog

Cutaneous

\begin{tabular}{|c|c|c|c|}
\hline & & & $\begin{array}{l}\text { LSU: Li et al. } \\
\text { (2017) }\end{array}$ \\
\hline $\begin{array}{l}\text { Subcutaneous infection, } \\
\text { horse }\end{array}$ & Pavia, Pavia, Italy & JF747094 & $\begin{array}{l}\text { de Hoog et al. } \\
\text { (2011) }\end{array}$ \\
\hline $\begin{array}{l}\text { Root of Hordeum vulgare } \\
\text { L. }\end{array}$ & $\begin{array}{l}\text { Noordoostpolder, } \\
\text { Flevoland, } \\
\text { Netherlands }\end{array}$ & KF928494 & $\begin{array}{l}\text { Attili-Angelis et } \\
\text { al. (2014) }\end{array}$ \\
\hline $\begin{array}{l}\text { Lung tissue of Galapagos } \\
\text { tortoise }\end{array}$ & Chicago, Illinois, USA & KF928497 & $\begin{array}{l}\text { Attili-Angelis et } \\
\text { al. (2014) }\end{array}$ \\
\hline $\begin{array}{l}\text { Straw in an armadillo } \\
\text { burrow }\end{array}$ & Uruguay & AY156973 & $\begin{array}{l}\text { Vitale and de } \\
\text { Hoog (2002) }\end{array}$ \\
\hline Axillary skin, human & $\begin{array}{l}\text { San Antonio, Texas, } \\
\text { USA }\end{array}$ & JF747108 & $\begin{array}{l}\text { de Hoog et al. } \\
\text { (2011) }\end{array}$ \\
\hline Wood pulp & Sweden & AY857524 & $\begin{array}{l}\text { Prenafeta-Boldú } \\
\text { et al. (2006) }\end{array}$ \\
\hline $\begin{array}{l}\text { Big toe nail infection, } \\
\text { human }\end{array}$ & Hong Kong, China & JN625231 & $\begin{array}{l}\text { Woo et al. } \\
\text { (2013) }\end{array}$ \\
\hline Human & Unknown & AF050271 & $\begin{array}{l}\text { Untereiner and } \\
\text { Naveau (1999) }\end{array}$ \\
\hline Lake water & $\begin{array}{l}\text { Loosdrecht, North } \\
\text { Holland, Netherlands }\end{array}$ & JF747110 & $\begin{array}{l}\text { de Hoog et al. } \\
\text { (2011) }\end{array}$ \\
\hline
\end{tabular}

Muga River mouth,

Ampuriabrava, KU705830 KU705847 This study Girona, Spain

Unknown

AY857528

Prenafeta-Boldú et al. (2006)

Untereiner and Naveau (1999)

de Hoog et al. (2011)

Li et al. (2017)

St. Petersburg,

Northwestern Federal KF881967

Zeng and de

Former USSR

EF551550

Hoog (2008)

de Hoog et al.

(2003)

de Hoog et al.

(2011)

Irinyi et al. (2015)

Ille et Villaine,
Brittany, France

Frankfurt-am-Main,

Hesse, Germany

Attili-Angelis et

KF928486 al. (2014)

Besòs River, Sant

Adrià del Besòs,

Barcelona, Spain

KU705831 KU705848 This study

CBS $131.88^{\top} \quad$ phaeohyphomycosis, Japan

AJ244259

de Hoog et al.

(1999b) 


\section{Taxon}

Exophiala pisciphila McGinnis \& Ajello

Exophiala polymorpha

Guarro, Sandoval-Denis,

Deanna A. Sutton \&

Wiederhold

Exophiala placitae Crous \&

Summerell

Exophiala psychrophila O.A. Pedersen \& Langvad

Exophiala radicis Maciá-
Vicente, Glynou \& M.
Piepenbr.

Exophiala salmonis J.W. Carmich.

\begin{abstract}
Isolate no.
\end{abstract}
CBS $537.73^{\top}$

CBS 138920

CBS 138920

CBS $121716^{\top}$

CBS $191.87^{\top}$

CBS $140402^{\top}$

10618

FMR 10620

FMR 10620

FMR 10881

Soi

FMR 10882 Soil

FMR $10884 \quad$ Soil

CBS $157.67^{\top}$

Cerebral infection Oncorhynchus clarkii Richardson

Substrate

Systemic mycosis in

channel catfish

human

Salmo salar $\mathrm{L}$.

Root of Microthlaspi

Soil

Soil
Subcutaneous lesion,

Leaf of Eucalyptus placita L.A.S. Johnson \& K.D. Hill perfoliatum (L.) F.K. Mey

10588

Exophiala sp.

Exophiala sp.

Exophiala sp.

Exophiala sideris Seyedm. \& de Hoog

Exophiala spinifera (H.S. Nielsen \& Conant) McGinnis

Exophiala tremulae W. Wang UAMH $10998^{\top}$

Exophiala xenobiotica de Hoog, J.S. Zeng, Harrak \& Deanna A. Sutton

Fonsecaea brasiliensis V.A. Vicente, Najafz., C.H.W.

Klaassen \& de Hoog

Fonsecaea erecta V.A

Vicente, Najafz., Sun \& de Hoog

Fonsecaea monophora (M Moore \& F.P. Almeida) de Hoog, V.A. Vicente \& D. Attili CBS 102238

Fonsecaea minima V.A.
CBS $118157^{\top}$

CBS $119710^{\top}$

CBS 119718

CBS 125762

CBS 125763

\section{CBS $121818^{\top}$}

CBS $899.68^{\top}$ aucuparia $\mathrm{L}$.

Nasal granuloma, human USA

Roots of Populus tremuloides Michx

Oil sludge

Scylla serrata Forsskål (mangrove crab)

Scylla serrata Forsskål (mangrove crab)

Leaf of Orbignya phalerata Mart.

Spine of Smilax sp.

Chromoblastomycosis, human

Soil

CBS 125760

\section{Geographical origin}

EMBL accession \#

LSU

References

Central Alabama, USA AF050272

Untereiner and

Naveau (1999)

Yong et al

(2015)

Bimbadeen Lookout

New South Wales, EU040215 Crous et al.

Australia

(2007a)

de Hoog et al.

(2011)

Near Buchen, Baden-

Württemberg, KT099204 KT723448 Maciá-Vicente et

Germany

al. (2016)

Near Besande, León, KU705834 KU705851 This study

Spain

Olleros de Alba, León, KU705835 KU705852 This study Spain

Sierra de Monegros, KU705836 KU705853 This study Teruel, Spain

Fuente de

Matahombres, $\quad$ KU705837 KU705854 This study

Teruel, Spain

Puerto de San Rafael,

Teruel, Spain

KU705838 KU705855 This study

ITS: Untereiner and Naveau

Calgary, Alberta

Canada (1999)

LSU: Rakeman et al. (2005)

La Mussara Tarragona, Spain KU705832 KU705849 This study Vigaña d'Arcéu, Belmonte de Miranda, Spain

KU705833 KU705850 This study

Mora de Rubielos, Teruel, Spain

KU705839 KU705856 This study

Netherlands

HQ452311

Seyedmousavi et al. (2011)

Vitale and de

AY156976 Hoog (2002)

Lamont, Alberta, FJ665274 JF951155 Crous et al.

Canada

(2011)

San Tomé,

Anzoategui,

DQ182587

de Hoog et al.

Venezuela

(2006)

Brazil

JN173784

Vicente et al.

(2012)

Brazil JN173785

Vicente et al.

Fortaleza, Maranhao,

Brazil

KC886413

Vicente et al.

(2014)

Vicente et al.

(2014)

Prenafeta-Boldú

et al. (2006)

de Hoog et al.

(2004)

Vicente et al. 


\section{Taxon}

Vicente, Najafz., Sun \& de Hoog

Fonsecaea multimorphosa
Najafz., V.A. Vicente, Sun,
Meis \& de Hoog
Fonsecaea nubica Najafz.,
Sun, V.A. Vicente, L. Xi, Van
den Ende \& de Hoog
Fonsecaea pedrosoi (Brumpt)
Negroni
Fonsecaea pugnacius R.R.
Gomes, V.A. Vicente, C.M.P.S.
Azevedo \& de Hoog
Phaeomoniella prunicola
Damm \& Crous
"Phialophora" livistonae
Crous \& Summerell
(= Cyphellophora livistonae
(Crous \& Summerell) Madrid
\& Hern.-Restr., comb. nov.)
Phialophora verrucosa
Medlar

Rhinocladiella anceps (Sacc. \& Ellis) S. Hughes

Rhinocladiella aquaspersa (Borelli) Schell, McGinnis \& Borelli

Rhinocladiella atrovirens Nannf.

Rhinocladiella basitona (de Hoog) Arzanlou \& Crous

Rhinocladiella fasciculata (V. Rao \& de Hoog) A rzanlou \& Crous

Isolate no.

\section{CBS 125761}

CBS $980.96^{\top}$

CBS $269.64^{\top}$

CBS 444.62

CBS $271.37^{\top}$

CBS $139214^{\top}$

dH 24207

CBS $120876^{\top}$

CBS $133589^{\top}$

CBS

MUCL 9760

CBS $181.65^{\top}$

CBS $313.73^{\top}$

human

CBS 122635

CBS $317.33^{\top}$

Chromoblastomycosis, human

Pine wood

CBS 264.49

CBS $101460^{\top}$

Honey

Subcutaneous lesion,

human

CMCC(F)D.37C

Lesion on facial skin,

human

Decaying wood

Cerebral

Rhinocladiella mackenziei
(C.K. Campb. \& Al-Hedaithy) Arzanlou \& Crous

CBS $650.93^{\top}$

phaeohyphomycosis, human

CBS 368.92 Brain abscess, Human

Rhinocladiella phaeophora Veerkamp \& W. Gams

CBS $496.78^{\top}$

Rhinocladiella similis de Hoog CBS $111763^{\top}$

Maize field soil

\section{Geographical origin}

Brazil

Icatu, Maranhao,

Brazil

Queensland, Australia JF267657

MBL accession \#

ITS

LSU

References

(2014)

Vicente et al.

(2014)

Najafzadeh et al. (2011)

Najafzadeh et al. (2010)

de Hoog et al.

(2004)

de Hoog et al.

(2004)

de Azevedo et al.

de Azevedo et al. (2015)

Maranhão, Brazil

KR70655

Mookgopong,

Limpopo, South

Africa

GQ154614 $\begin{aligned} & \text { Damm et al. } \\ & \text { (2010) }\end{aligned}$

Litchfield National

Park, Northern

Territory, Australia

KC005774 KC005796 Crous et al.

(2012b)

Brazil

EF413615 Geiser et al (2006)

EU041805 EU041862 Arzanlou et al.

Campbellville,

Ontario, Canada

(2007)

ITS: Badali et al. (2010)

GU017733 AB100677

LSU: Abliz et al. (2004b)

Mexico City, Mexico

GU017732

Badali et al.

(2010)

Sweden

AB091215

Abliz et al. (2003)

Ille et Villaine, Brittany, France

Hamamatsu

Shizuoka, Japan

China

Arzanlou et al.

(2007)

EU041806 EU041863 Arzanlou et al.

(2007)

JX981676

Cai et al. (2013)

Thirathahalli,

Karnataka, India

EU041807 EU041864 Arzanlou et al.

(2007)

ITS: PrenafetaBoldú et al. (2006)

AY857540 AF050288

LSU: Untereiner and Naveau (1999)

Haifa, Haifa district, Israel

Arzanlou et al. (2007)

Near Villavicencio,

Meta, Colombia

EU041809

EU041811 EU041868 Arzanlou et al

(2007)

Cutaneous ulcer, human

Minas Gerais, Brazil

EF551461

Zeng and de 


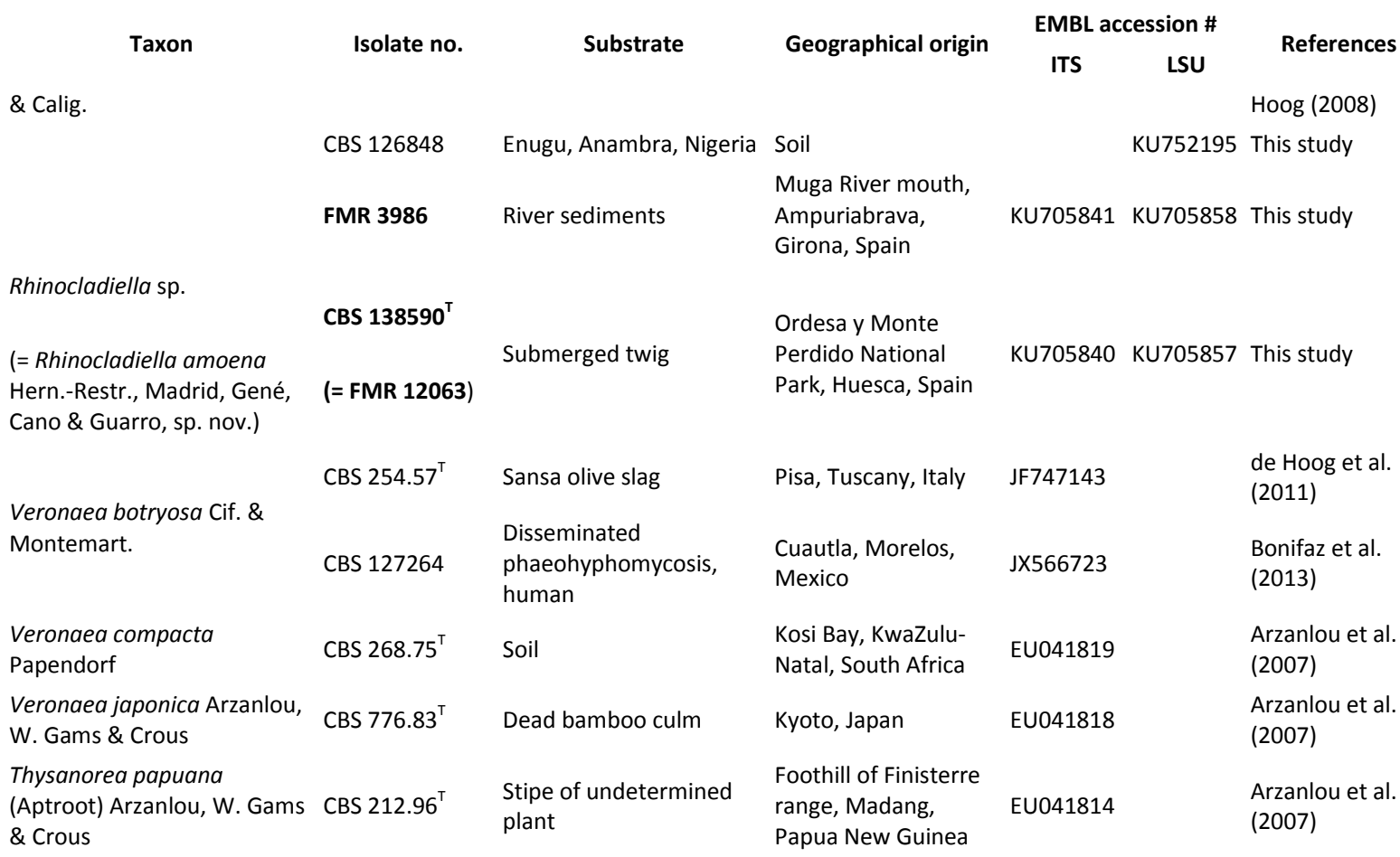

ATCC American Type Culture Collection, Bethesda, Maryland, USA, CBS CBS-KNAW Fungal Biodiversity Centre, Utrecht, The Netherlands, CG Cécile Gueidan, Natural History Museum, Department of Botany, London, United Kingdom, CGMCC China General Microbiological Culture Collection, Beijing, China, CMCC China Medical Culture Collection, National Institute for the Control of Pharmaceutical and Biological Products, Beijijng, China, CPC Pedro Crous Working Collection, housed at CBS, dH Sybren de Hoog Working Collection, housed at CBS, FMR Faculty of Medicine collection, Reus, Spain, KACC Korean Agricultural Culture Collection, National Academy of Agricultural Science, Seoul, Korea, MFC Matsushima Fungus Collection, Kobe, Japan, MUCL Mycothèque de L'Université Catholique de Louvain, Faculté des Sciences Agronomiques, Louvain-laNeuve, Belgium, UAMH University of Alberta Microfungus Collection and Herbarium, Devonian Botanic Garden, Edmonton, Canada

\section{Results}

\section{Molecular and morphological study}

BLAST searches allowed us to identify 10 out of the 16 studied strains to species level. They belong to Cyphellophora suttonii $(n=1)$, Exophiala aquamarina $(n=1)$, E. radicis $(n=5), E$. lacus $(n=1)$, E. oligosperma $(n=1)$ and Rhinocladiella similis $(n=1)$. All of those strains had ITS sequence identities $\geq 99 \%$ to the ex-type or representative strains of each of those species, and clustered with them in LSU and ITS phylogenies (Figs. 1, 3, 4, 5). The only species for which no reference LSU sequences were available in GenBank were $E$.

aquamarina and E. lacus, and these species were represented only by strains from Spain in the LSU tree (Fig. 1). The ex-type strains of both species, however, were included in an ITS tree of Exophiala spp. (Fig. 4). Three strains, i.e. FMR 10588, FMR 10592, and FMR 10880 showed $99 \%$ ITS sequence identities to the ex-type strains of both E. radicis (CBS 140402, GenBank KT099204) and E. tremulae (UAMH 10998, GenBank FJ665274). We decided to keep these FMR strains provisionally as "Exophiala sp." (Table 1; Figs. 1, 4), and in a future study more loci will be analyzed to determine their final identifications. In the Exophiala ITS tree (Fig. 4), these strains, E. equina, E. radicis, E. salmonis and E. tremulae could not be properly separated. This was probably caused by the loss of informative sites located within ambiguously aligned positions which had to be excluded from the analysis. A higher level of resolution might be obtained in an ITS tree including only those species and very closely 
related ones, but such phylogenetic analysis was considered unnecessary since identifications of Exophiala spp. in this paper are mainly based on ITS percent identities revealed by BLAST search results. Strains CBS 127581, CBS 138590, and CBS 138591 showed ITS identities $\leq 97 \%$ to known members of the Chaetothyriales, suggesting that they might represent novel taxa.

Strain CBS 127581 did not sporulate on OA or PCA, but produced some chlamydospores on MEA. The closest matches for its ITS sequence were Cyphellophora europaea CBS 101466, ex-type (GenBank EU514698) and other strains of the same species, 91-92 \% identical, and C. phyllostachydis CGMCC3.17495, ex-type (GenBank KP010371), 91 \% identical. Strain CBS 138590 produced melanized, sympodial, denticulate conidiophores and aseptate conidia typical of the genus Rhinocladiella (Arzanlou et al. 2007), but its morphological features did not match any of the currently accepted species (see "Taxonomy"). The closest match in a BLAST search with its ITS sequence, however, was Exophiala dermatitidis CBS 207.35, extype (GenBank AF050269) and other strains, 83-84 \% identical. Strain CBS 138591 produced acropetal, branched chains of elongate, olivaceous brown blastic conidia from undifferentiated to moderately differentiated conidiophores, resembling members of Cladophialophora (Badali et al. 2008). BLAST searches revealed that its closest relatives are C. chaetospira CBS 491.70 (GenBank EU035405) and other strains, 96-97\% identical, and C. parmeliae CBS 129337 (GenBank JQ342180), 95 \% identical.

The best substitution models chosen by MEGA 6 were $\mathrm{K} 2+\mathrm{G}+\mathrm{I}$ for the general LSU, the Cladophialophora ITS and the Exophiala ITS datasets, and $\mathrm{K} 2+\mathrm{G}$ for the Cyphellophora ITS and Rhinocladiella ITS datasets. In the LSU phylogenetic tree (Fig. 1), strain CBS 127581 appeared within a clade with $100 \%$ bootstrap support (bs) which represents the genus Cyphellophora. The strain appeared as a novel lineage clearly separated from other species of this genus. In the Cyphellophora ITS tree (Fig. 3), strain CBS 127581 grouped with C. europaea and C. phyllostachidis with $81 \%$ bs, but also appeared as a clearly distinct taxon, separated from these species by a considerable genetic distance. The ex-type strain of Phialophora livistonae (CBS 133589), included in the phylogenetic analyses, clustered with the Cyphellophora clade, which is quite distant from the type species of the genus Phialophora, P. verrucosa (Fig. 1). LSU and ITS-based phylogenies proved that the Rhinocladiella sp. strain CBS 138590 is clearly distinct from all members of that genus and similar fungi sequenced so far (Figs. 1, 5). In the LSU tree, it clustered with low support with three strains of unidentified Chaetothyriales associated with ant galleries from a study by Nepel et al. (2014). In the LSU tree, the Cladophialophora sp. strain CBS 138591 grouped with $94 \%$ bs with Cladophialophora parmeliae, and both species were separated by relatively short branch lengths. Their morphological features, however, are remarkably different (see section Taxonomy). In the Cladophialophora ITS tree (Fig. 2), strain CBS 138591 grouped with C. chaetospira, C. floridana, and C. multiseptata, with low bs., but appeared as a clearly different species. Molecular and morphological data justify the proposal of three novel species of Cyphellophora, Rhinocladiella and Cladophialophora, based on strains CBS 127581, CBS 138590 and CBS 138591, respectively, as well as a new combination for Phialophora livistonae in Cyphellophora. 


\section{Taxonomy}

Cladophialophora pseudocarrionii Madrid, Hern.-Restr., Gené, Cano \& Guarro, sp. nov., Fig. 6
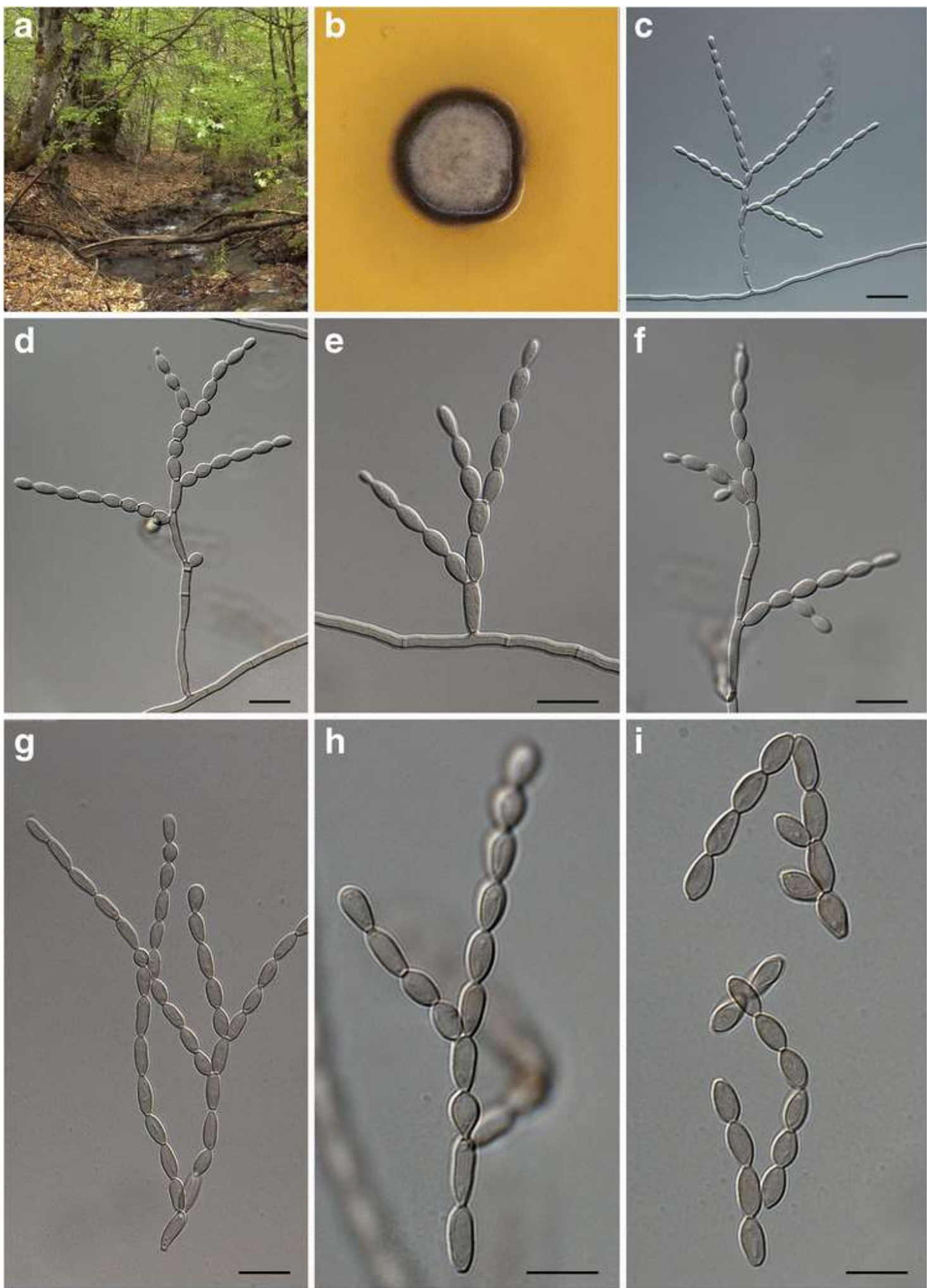

Fig. 6. Cladophialophora pseudocarrionii (CBS 138591). a Sampling area in Hayedo de la Tejera Negra Natural Park. b Colony on MEA after $14 \mathrm{~d}$ at $24^{\circ} \mathrm{C}$. c-f Conidiophores, conidiogenous cells and conidia. g-i Conidial chains. Scale bars (c) $20 \mu \mathrm{m},(\mathbf{d}-\mathbf{i}) 10 \mu \mathrm{m}$ 


\section{MycoBank:MB815961}

Etymology: the name refers to the morphological similarity between this fungus and the generic type, $C$. carrionii

Colonies after 14 days at $24^{\circ} \mathrm{C}$ attaining $6 \mathrm{~mm}$ on MEA and 8-9 mm on OA, cottony, olivaceous gray and elevated at the center, glabrous and fuscous black toward the periphery, with an entire margin and hyaline exudates; reverse black. Vegetative hyphae septate, branched, subhyaline to light olivaceous brown, smooth- and thin-walled, 2-3 $\mu \mathrm{m}$ wide. Conidiophores micronematous to semimacronematous, sometimes reduced to conidiogenous cells, pale olivaceous brown. Conidiogenous cells subcylindrical, 7.5-19 × 2$3 \mu \mathrm{m}$. Conidia in acropetal, branched, strongly coherent chains, mostly ellipsoid to fusiform, aseptate (very rarely 1-septate), subhyaline to pale brown, smooth-walled, 5.5-9.5 $\times 2-$ $4.5 \mu \mathrm{m}$; ramoconidia 4-15 × 3-4 $\mu \mathrm{m}$. Chlamydospores and sexual morph not observed. Optimum growth temperature $24^{\circ} \mathrm{C}$, minimum below $6{ }^{\circ} \mathrm{C}$, maximum between 24 and $30^{\circ} \mathrm{C}$.

Material examined: SPAIN. Guadalajara Province, Hayedo de la Tejera Negra Natural Park, isolated from soil, May 2011, M. Hernández Restrepo, J. Guarro \& J. Mena Portales (CBS H21836 holotype, a dried culture on MEA; ex-type cultures CBS 138591 and FMR 12062).

Notes: This new species is morphologically very different from its closest relatives, $C$. parmeliae and $C$. chaetospira. Cladophialophora parmeliae is a sporodochium-forming species which produces 1-septate, verrucose conidia which frequently remain attached to each other laterally, forming strongly flexuous chains (Diederich et al. 2013).

Cladophialophora chaetospira, on the other hand, clearly differs from the new species in producing chains of much longer conidia $(20-45 \times 3-5 \mu \mathrm{m})$ with 1-3 septa (Crous et al. 2007b).

Cladophialophora pseudocarrionii more closely resembles the type species of the genus, $C$. carrionii, and its closest relative, $C$. yegresii, by the ability to produce repeatedly branched chains of aseptate, ellipsoid to fusiform conidia. Cladophialophora carrionii and C. yegresii, however, tolerate higher temperatures (both species can grow at $37^{\circ} \mathrm{C}$; de Hoog et al. 2007). Furthermore, a phialidic synasexual stage occasionally produced by $C$. carrionii (de Hoog et al. 2000), was not observed in C. pseudocarrionii.

Cyphellophora chlamydospora Madrid, Hern.-Restr., Cano, Gené, Guarro \& V. Silva, sp. nov. Fig. 7 

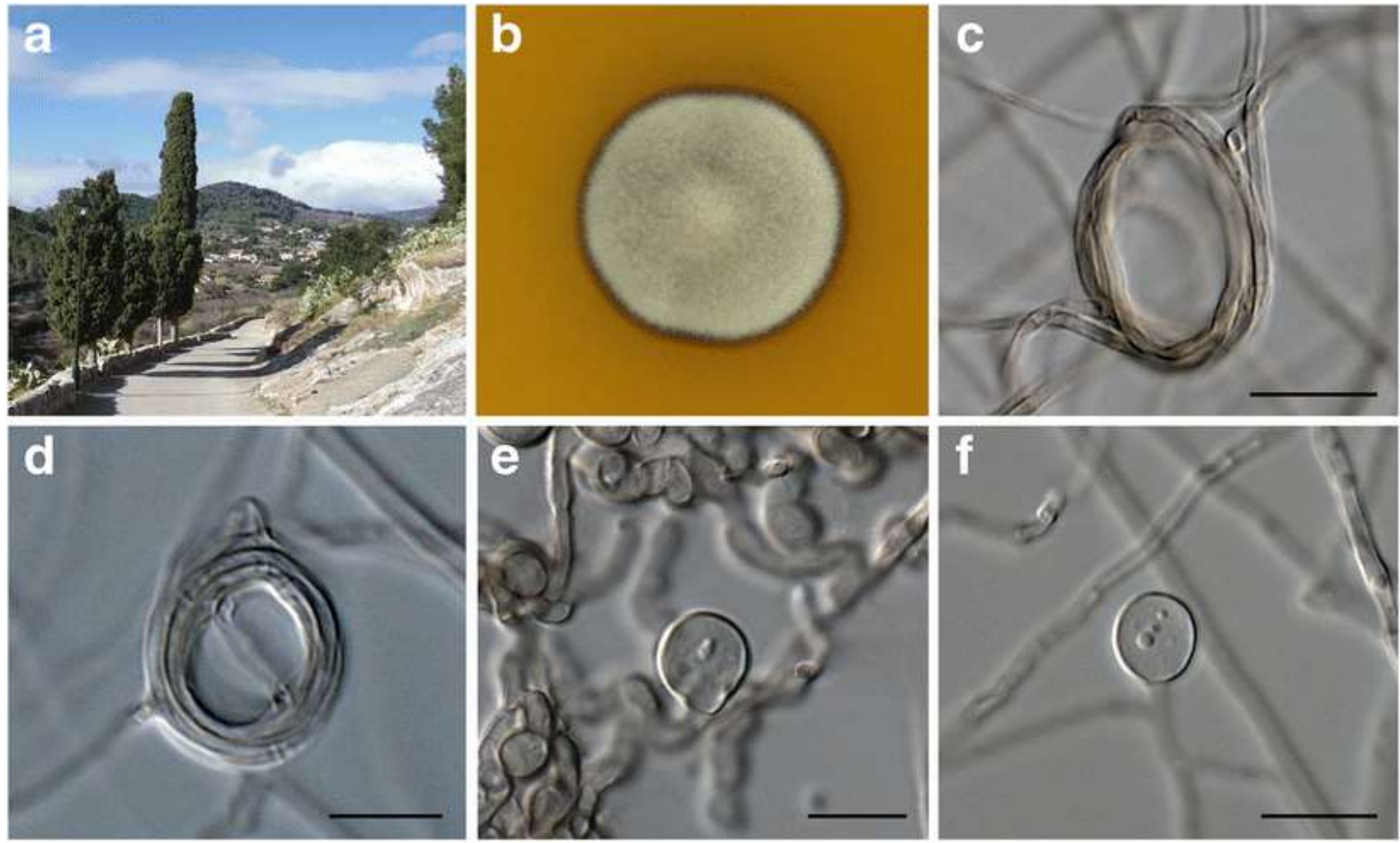

Fig. 7. Cyphellophora chlamydospora (CBS 127581). a Sampling area in Castellvell del Camp. b Colony on MEA after $14 \mathrm{~d}$ at $24^{\circ} \mathrm{C}$. c, d Hyphal coils. e, f Chlamydospores. Scale bars (c-f ) $10 \mu \mathrm{m}$

\section{MycoBank:MB809813}

Etymology: The name refers to the chlamydospores produced by the fungus in culture

Colonies after 14 days at $24{ }^{\circ} \mathrm{C}$ attaining $21 \mathrm{~mm}$ on MEA and $23 \mathrm{~mm}$ on OA, velvety, gray, with an olivaceous black, entire margin; reverse olivaceous black. Vegetative hyphae septate, branched, straight to flexuous, pale olivaceous to pale olivaceous brown, smoothand thin-walled, 1.5-4 $\mu \mathrm{m}$ wide, forming strands and coils, with anastomoses, often appearing irregular and constricted at the septa, especially in cultures at $30^{\circ} \mathrm{C}$. Chlamydospores mostly subglobose, aseptate, pale olivaceous to pale olivaceous brown, smooth-walled, 6.5-13.5 $\mu \mathrm{m}$ wide. Conidia, yeast cells and sexual morph not observed. Optimum growth temperature $24^{\circ} \mathrm{C}$, minimum below $6{ }^{\circ} \mathrm{C}$, maximum between 30 and $36^{\circ} \mathrm{C}$.

Material examined: SPAIN. Tarragona Province, Castellvell del Camp, isolated from soil, February 2010, H. Madrid (CBS H-21629 holotype, a dried culture on MEA; ex-type cultures CBS 127581and FMR 10878).

Notes: Cyphellophora chlamydospora is an atypical member of this genus by its inability to produce conidia on common mycological media (Feng et al. 2012). However, in spite of its poor morphology, it was possible to place it in the genus Cyphellophora based on DNA sequence analyses. In this strain, chlamydospores were abundant at $30^{\circ} \mathrm{C}$, but were less frequent at lower temperatures, suggesting that thermal stress might stimulate their production when approaching the maximum tolerated. None of the species currently accepted in Cyphellophora has been reported to produce chlamydospores in culture 
(Matsushima 1987; de Hoog et al. 2000; Decock et al. 2003; Cheewangkoon et al. 2009; Feng et al. 2012; Réblová et al. 2013; Gao et al. 2015; Crous et al. 2016). Hyphal coils were abundant in $C$. chlamydospora, but these are also produced by many other species of Cyphellophora as well as other genera of Chaetothyriales (Feng et al. 2012; Crous et al. 2007b, 2013), and are morphologically very variable, indicating that they are not taxonomically informative.

As previously mentioned, a species originally described in Phialophora, P. livistonae, proved to belong in Cyphellophora, and clustered with 100 and $97 \%$ bs with C. sessilis in LSU and ITS-based phylogenetic analyses (Figs. 1 and 3, respectively). Both species are similar in producing abundant intercalary phialides and elongate, rather short and non-falcate conidia. They differ, however, in conidial size, i.e. 4-10 $\times 2-3.5 \mu \mathrm{m}$ in P. livistonae and about $3 \times 1.8 \mu \mathrm{m}$ in C. sessilis (de Hoog et al. 1999a; Crous et al. 2012a). Phialophora livistonae is transferred to Cyphellophora and the following new combination is proposed:

Cyphellophora livistonae (Crous \& Summerell) Madrid \& Hern.-Restr., comb. nov. Mycobank:MB809814

इ Phialophora livistonae Crous \& Summerell, Persoonia 29: 169 (2012)

Rhinocladiella amoena Hern.-Restr., Madrid, Gené, Cano \& Guarro, sp. nov. Fig. 8 

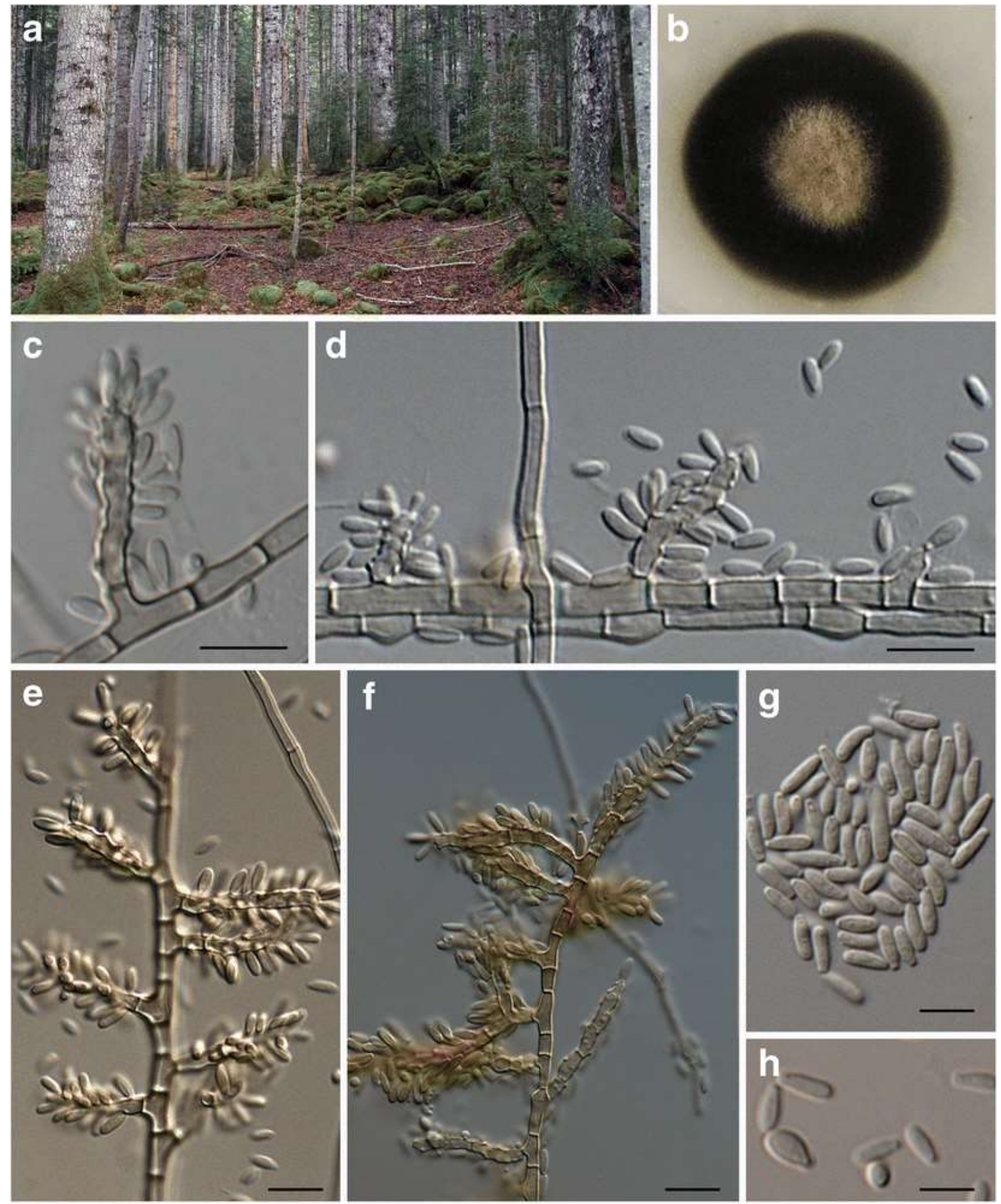

Fig. 8. Rhinocladiella amoena (CBS 138590). a Sampling area in Ordesa y Monte Perdido National Park. b Colony on OA after 14 days at $24{ }^{\circ} \mathrm{C}$. c-f Conidiophores, conidiogenous cells and conidia. $\mathbf{g}, \mathbf{h}$ conidia. Scale bars (c-f) $10 \mu \mathrm{m},(\mathbf{g}, \mathbf{h}) 5 \mu \mathrm{m}$ 


\section{MycoBank:MB815962}

Etymology: The name derives from Latin "amoenus", meaning "delightful"

Colonies after 14 days at $24^{\circ} \mathrm{C}$ attaining $6 \mathrm{~mm}$ on MEA and 13-16 mm on OA, dry, cottony and grayish sepia at the center, glabrous and fuscous black at the periphery, with an entire margin; reverse black. Vegetative hyphae septate, branched, subhyaline, smooth- and thinwalled, 1-2.5 $\mu \mathrm{m}$ wide. Conidiophores semimacronematous to macronematous, simple to profusely branched, light to dark olivaceous brown, rather thick-walled, up to $43 \mu \mathrm{m}$ long and $3 \mu \mathrm{m}$ wide. Conidiogenous cells mostly terminal, cylindrical, olivaceous-brown, 4.5$20 \times 1.5-3 \mu \mathrm{m}$, producing conidia sympodially on numerous small denticles. Conidia obovoid, subcylindrical to narrowly clavate, aseptate, pale olivaceous, 3-6 $\times 1-2 \mu \mathrm{m}$, with an obtuse apex and a truncate base with an inconspicuous scar. Chlamydospores, yeast cells and sexual morph not observed. Optimum growth temperature $24{ }^{\circ} \mathrm{C}$, minimum between 6 and $12{ }^{\circ} \mathrm{C}$, maximum between 30 and $36^{\circ} \mathrm{C}$.

Material examined: SPAIN. Huesca Province, Ordesa y Monte Perdido National Park, isolated from a submerged twig, 26 March 2011, M. Hernández-Restrepo \& J. Capilla (CBS H-21835 holotype, a dried culture on MEA; ex-type cultures CBS 138590 and FMR 12063).

Notes: This fungus is superficially similar to other Rhinocladiella species with branched conidiophores, such as $R$. anceps, $R$. atrovirens, $R$. basitona and $R$. similis. However, they can be distinguished by conidial morphology and size, i.e. subglobose to ellipsoidal and 2.5$3.8 \times 1.8-2.5 \mu \mathrm{m}$ in $R$. anceps, short-cylindrical and 3.7-5.5 $\times 1.2-1.8 \mu \mathrm{m}$ in $R$. atrovirens, guttuliform to clavate and 3.5-4.5 $\times 2.2 \mu \mathrm{m}$ in $R$. basitona, and cylindrical, $4-7 \times 1.5 \mu \mathrm{m}$ in $R$. similis (de Hoog and Hermanides-Nijhof 1977; de Hoog et al. 2003). Furthermore, the yeast cells that are often produced in culture by $R$. anceps, $R$. atrovirens and $R$. similis (de Hoog and Hermanides-Nijhof 1977; de Hoog et al. 2000, 2003) were not observed in $R$. amoena.

\section{Discussion}

Most of the best-known hyphomycetous genera in the Chaetothyriales are polyphyletic within the order (Crous et al. 2007b; Gueidan et al. 2014). Traditionally, they have been defined by morphological features (de Hoog et al. 2000), which later proved to have emerged many times in separate, often relatively distant, phylogenetic groups (Arzanlou et al. 2007; Crous et al. 2007b; Badali et al. 2008; Najafzadeh et al. 2011). One of such genera is Cladophialophora, defined by the production of globose to elongate, acropetal, usually branched chains of blastic, melanized conidia with inconspicuous scars (Badali et al. 2008; Bensch et al. 2012). The generic type, C. carrionii, belongs in Herpotrichiellaceae, but many other species are related to other chaetothyrialean families, such as Epibryaceae, Chaetothyriaceae and Trichomeriaceae (Gueidan et al. 2014). Even outside the Chaetothyriales, species of the genus Fusicladium (Venturiaceae, Pleosporales) may show morphological features which closely resemble those of Cladophialophora (Crous et al. 2007b; Koukol 2010). The new species described in this paper, however, is related to members of the Herpotrichiellaceae (Fig. 1) and can undoubtedly be considered a member of Cladophialophora s. str. 
The genus Cyphellophora originally included dematiaceous, phialidic chaetothyrialean fungi with falcate, septate conidia (de Vries 1962; de Hoog et al. 2000; Decock et al. 2003). Conidial morphology was the main difference between this genus and Phialophora, which typically produces aseptate, mostly globose to ellipsoid conidia (Schol-Schwarz 1970; Gams 2000). Phylogenetic studies revealed that typical Cyphellophora species formed a paraphyletic group which also included certain members of Phialophora with non-falcate conidia (Feng et al. 2012). Two species with atypical morphology, i.e. C. eugeniae and C. hylomeconis (Crous et al. 2007b), clustered outside that group and were later transferred to the segregate genera Aphanophora and Camptophora, respectively. In culture, Aphanophora produces setae and subcylindrical to cylindrical conidia with constrictions at the septa, whereas Camptophora produces fusiform to falcate conidia with a tendency to anastomose and undergo microcyclic sporulation (Réblová et al. 2013). With the reallocation of those atypical species and the inclusion of genetically related members of Phialophora, the genus Cyphellophora was redelimited to become a monophyletic entity (Réblová et al. 2013). In our study, one new Cyphellophora species, C. chlamydospora, was proposed and $C$. suttonii is reported for the first time from Europe, isolated from garden soil in Catalonia. The latter species was originally described as an agent of subcutaneous phaeohyphomycosis in a dog in USA (Ajello et al. 1980) and was later reported from a human infection in the same country (Perfect and Schell 1996) and from soil in Brazil (Nunes et al. 1999). However, the identity of the strains from human and soil have not been confirmed molecularly. In the present study, one more Phialophora s.l. species, P. livistonae, was transferred to Cyphellophora based on DNA sequence data (Figs. 1, 3). Since the type species of Phialophora, P. verrucosa, is a member of Herpotrichiellaceae (de Hoog et al. 1999a), many other Phialophora s.l. species related to different taxonomic groups have been reallocated to other genera, such as Cadophora (Helotiales), Gaeumannomyces (as "Harpophora", Magnaporthaceae), Phaeoacremonium (Togniniaceae), Pleurostomophora (Pleurostomataceae) and others (Crous et al. 1996; Gams 2000; Harrington and McNew 2003; Vijaykrishna et al. 2004; Réblová et al. 2013). Despite these advances in the taxonomy of Phialophora s.l., many species have been described without a proper molecular study (e.g. Millar 1990; Jiang and Wang 2010; Wu and Zhang 2011) and their phylogenetic placement still needs to be assessed.

The Cyphellophora clade, which is strongly supported, shows a considerable degree of genetic diversity and appeared clearly separated from the accepted families of Chaetothyriales (Feng et al. 2012; Réblová et al. 2013). Therefore, it was considered by Réblová et al. (2013) to be a distinct, monotypic family, the Cyphellophoraceae. However, in the phylogenetic analysis by Gueidan et al. (2014), two species of Cladophialophora s.l., i.e. C. hostae and C. scillae, formed a sister group to the Cyphellophora clade and were also included in the Cyphellophoraceae. These species, which form cladosporoid, acropetal chains of holoblastic conidia (Crous et al. 2007b), are morphologically and phylogenetically clearly distinct from the core of the genus Cyphellophora, in which only phialidic conidiogenesis has been described (Feng et al. 2012; Réblová et al. 2013), and evidently should not be transferred to this genus. Cladophialophora hostae and C. scillae should be kept, at least provisionally, under the broad, polyphyletic current concept of Cladophialophora. 
Rhinocladiella includes dematiaceous hyphomycetes with more or less differentiated, sympodial conidiophores with a denticulate rachis and aseptate, usually elongate conidia, but Exophiala-like yeast stages are observed in several species of this genus (de Hoog and Hermanides-Nijhof 1977). Species of Rhinocladiella appear in different clades of Chaetothyriales, sometimes in association with genera such as Exophiala and the sexual morph Capronia (Arzanlou et al. 2007; Crous et al. 2007b; Pratibha and Prabhugaonkar 2015). Strain CBS 138590 fits well in the current concept of Rhinocladiella, but its morphological and phylogenetic features clearly indicate that it is a novel taxon. In this paper, we also report $R$. similis, which is a relatively poorly-known species described originally from a cutaneous ulcer in a patient from Brazil (de Hoog et al. 2003). The CBS fungal collection (http://www.cbs.knaw.nl/Collections/) also includes strains of $R$. similis from bathroom surfaces, bronchial wash and soil, from different geographic regions. The only chaetothyrialean genus with which Rhinocladiella might be confused is Veronaea, but species of the latter genus typically have 1-septate conidia (de Hoog and Hermanides-Nijhof 1977). Thysanorea is also superficially similar, but produces both micronematous and macronematous conidiophores, the latter ones with a dark brown, thick-walled stalk and a head formed by a complex system of branches. The conidiogenous cells of Thysanorea have denticles much more prominent than those of Rhinocladiella and, as in Veronaea, its conidia are septate (Arzanlou et al. 2007; Pratibha and Prabhugaonkar 2015). Many hyphomycetous genera outside Chaetothyriales produce a conidial apparatus similar to that of Rhinocladiella, e.g. Myrmecridium (Myrmecridiaceae, Sordariomycetes), Pseudoramichloridium (Teratosphaeriaceae, Capnodiales), Radulidium (incertae sedis, Sordariomycetes), Ramichloridium (Mycosphaerellaceae, Capnodiales), Rhodoveronaea (Annulatascaceae, Sordariomycetes), and Veronaeopsis (close to Venturiaceae, Pleosporales), probably reflecting convergent evolution (Arzanlou et al. 2007; Cheewangkoon et al. 2009).

During the present study, four Exophiala spp. were identified, i.e. E. aquamarina, E. lacus, E. oligosperma, and E. radicis, isolated from soil and river sediments (Table 1). Exophiala aquamarina was previously known only from Canada and USA, associated with infections in a number of fish hosts, including leafy and weedy seadragons, winter flounder, little tunny, lumpfish and sand lance. It causes necrotic skin lesions which may progress to systemic infections with angio- and osteotropism, but apparently not neurotropism (de Hoog et al. 2011; Seyedmousavi et al. 2013). Its presence in Europe raises concern about its possible role in phaeohyphomycosis in fishes in this continent, considering its broad range of hosts and its ability to cause aquarium outbreaks (de Hoog et al. 2011). An uncultured Exophiala sp. with $98 \%$ identity to the ex-type strain of E. aquamarina (CBS 119918) in the 18S rDNA gene was reported as one of the main fungi colonizing a marble monument in Germany (Hallmann et al. 2013). In that study, the fungus was identified as E. aquamarina but, taking into account its terrestrial habitat and that $18 \mathrm{~S}$ is a relatively conserved gene (Iwen et al. 2002), almost certainly the fungus on marble represents a different but related taxon. Exophiala radicis was recently described as an endophyte of the brassicaceous host Microthlaspi perfoliatum in Bulgaria, France and Germany, and was also isolated from other plant materials in different European countries. That fungus was also isolated from samples of human skin and nails, but its role in disease has not been properly demonstrated (MaciáVicente et al. 2016). Remarkably, this fungus was recovered from soil samples collected in different Spanish regions (Table 1), probably representing a widespread species in this 
country. Exophiala lacus was recently described from shallow freshwater in a lake in The Netherlands (de Hoog et al. 2011). The fungus was only known from the ex-type strain, CBS 117497 , and no infections by this organism have been reported so far. During our study, the known distribution of this species was expanded to Spain, but it has not been reported outside Europe. Exophiala oligosperma has a widespread, transoceanic geographical distribution and is associated with a broad clinical spectrum, which includes brain abscesses, disseminated infections, onychomycosis, rhinosinusitis, and other clinical manifestations (de Hoog et al. 2003; Kan et al. 2013; Woo et al. 2013; Wen et al. 2016). In Spain, a case of subcutaneous infection in a renal transplant recipient was published by González-López et al. (2007). In the environment, E. oligosperma has been isolated from various substrates, including pasteurized ice tea, drinking water networks, plastic, and the floor of a steam bath (Najafzadeh et al. 2013). However, as far as we know, our study is the first one to report this species from an aquatic environment, i.e. river sediments (Table 1).

The order Chaetothyriales is an ecologically and clinically important group of fungi, of which still little is known. Further work and the collaboration of the global mycological community are necessary to generate a more complete knowledge about their biodiversity, habitats, distribution and the role they play in different ecosystems.

\section{Acknowledgments}

We are indebted to Drs. Mohammad Javad Najafzadeh and Sybren de Hoog, CBS-KNAW Fungal Biodiversity Centre (Utrecht, The Netherlands) for comparing ITS sequences of the Exophiala strains included in this study with the black yeasts DNA sequence database of that institution. This work was supported by the Spanish Ministry of Economy and Competitivity, grant CGL2011-27185.

\section{References}

Abliz P, Fukushima K, Takizawa K, Nieda N, Miyaji M, Nishimura K (2003) Rapid identification of the genus Fonsecaea by PCR with specific oligonucleotide primers. J Clin Microbiol 41:873-876

Abliz P, Fukushima K, Takizawa K, Nishimura K (2004a) Specific oligonucleotide primers for identification of Cladophialophora carrionii, a causative agent of chromoblastomycosis. J Clin Microbiol 42:404-407

Abliz P, Fukushima K, Takizawa K, Nishimura K (2004b) Identification of pathogenic dematiaceous fungi and related taxa based on large subunit ribosomal DNA D1/D2 domain sequence analysis. FEMS Immunol Med Microbiol 40:41-49

Ajello L, Padhye AA, Payne M (1980) Phaeohyphomycosis in a dog caused by Pseudomicrodochium suttonii. Mycotaxon 12:131-136

Altschul SF, Gish W, Miller W, Myers EW, Lipman DJ (1990) Basic local alignment search tool. J Mol Biol 215:403-410

Arzanlou M, Groenewald JZ, Gams W, Braun U, Shin HD, Crous PW (2007) Phylogenetic and morphotaxonomic revision of Ramichloridium and allied genera. Stud Mycol 58:57-93 
Attili-Angelis D, Duarte APM, Pagnocca FC, Nagamoto NS, de Vries M, Stielow JB, de Hoog GS (2014) Novel Phialophora species from leaf-cutting ants (tribe Attini). Fungal Divers 65:65-75

Badali H, Gueidan C, Najafzadeh MJ, Bonifaz A, Gerrits van den Ende AHG, de Hoog GS (2008) Biodiversity of the genus Cladophialophora. Stud Mycol 61:175-191

Badali H, Carvalho VO, Vicente V, Attili-Angelis D, Kwiatkowski LB, Gerrits van den Ende AHG, de Hoog GS (2009) Cladophialophora saturnica sp. nov., a new opportunistic species of Chaetothyriales revealed using molecular data. Med Mycol 47:55-66

Badali H, Bonifaz A, Barrón-Tapia T, Vásquez-González D, Estrada-Aguilar L, Oliveira NM, Sobral Filho JF, Guarro J, Meis JF, de Hoog GS (2010) Rhinocladiella aquaspersa, proven agent of verrucous skin infection and a novel type of chromoblastomycosis. Med Mycol 48:696-703

Badali H, Prenafeta-Boldú FX, Guarro J, Klaassen CH, Meis JF, de Hoog GS (2011) Cladophialophora psammophila, a novel species of Chaetothyriales with a potential use in the bioremediation of volatile aromatic hydrocarbons. Fungal Biol 115:1019-1029

Bates ST, Reddy GS, Garcia-Pichel F (2006) Exophiala crusticola anam. nov. (affinity Herpotrichiellaceae), a novel black yeast from biological soil crusts in the Western United States. Int J Syst Evol Microbiol 56:2697-2702

Bensch K, Braun U, Groenewald JZ, Crous PW (2012) The genus Cladosporium. Stud Mycol 72:1-401

Bonifaz A, Davoudi MM, de Hoog GS, Padilla-Desgarennes C, Vásquez-González D, Navarrete G, Meis JF, Badali H (2013) Severe disseminated phaeohyphomycosis in an immunocompetent patient caused by Veronaea botryosa. Mycopathologia 175:497-503

Braun U, Crous PW, Dugan F, Groenewald JZ, de Hoog GS (2003) Phylogeny and taxonomy of Cladosporium-like hyphomycetes, including Davidiella gen. nov., the teleomorph of Cladosporium s. str. Mycol Prog 2:3-18

Cai Q, Lu G-X, Jiang YQ, Mei H, Hu S-Q, Xu H-B, Wu X-F, Shen Y-N, Liu W-D (2013) The first case of phaeohyphomycosis caused by Rhinocladiella basitona in an immunocompetent child in China. Mycopathologia 176:101-105

Cheewangkoon R, Groenewald JZ, Summerell BA, Hyde KD, To-anun C, Crous PW (2009) Myrtaceae, a cache of fungal biodiversity. Persoonia 23:55-85

Chomnunti P, Bhat DJ, Gareth Jones EB, Chukeatirote E, Bahkali AH, Hyde KD (2012)

Trichomeriaceae, a new sooty mould family of Chaetothyriales. Fungal Divers 56:63-76

Crous PW, Groenewald JZ (2011) Why everlastings don't last. Persoonia 26:70-84

Crous PW, Gams W, Wingfield MJ, Van Wyk PS (1996) Phaeoacremonium gen. nov. associated with wilt and decline diseases of woody hosts and human infections. Mycologia 88:786-796

Crous PW, Schroers H-J, Groenewald JZ, Braun U, Schubert K (2006) Metulocladosporiella gen. nov. for the causal organism of Cladosporium speckle disease of banana. Mycol Res 110:264-275

Crous PW, Groenewald JZ, Summerell B (2007a) Exophiala placitae. Fungal Planet, no. 17 
Crous PW, Schubert K, Braun U, de Hoog GS, Hocking AD, Shin H-D, Groenewald JZ (2007b)

Opportunistic, human-pathogenic species in the Herpotrichiellaceae are phenotypically similar to saprobic or phytopathogenic species in the Venturiaceae. Stud Mycol 58:185-217

Crous PW, Braun U, Wingfield MJ, Wood AR, Shin HD, Summerell BA, Alfenas AC, Cumagun CJ, Groenewald JZ (2009) Phylogeny and taxonomy of obscure genera of microfungi. Persoonia 22:139161

Crous PW, Groenewald JZ, Shivas RG, Edwards J, Seifert KA, Alfenas AC, Alfenas RF, Burgess TI, Carnegie AJ, Hardy GE, Hiscock N, Hüberli D, Jung T, Louis-Seize G, Okada G, Pereira OL, Stukely MJC, Wang W, White GP, Young AJ, McTaggart AR, Pascoe IG, Porter IJ, Quaedvlieg W (2011) Fungal planet description sheets: 69-91. Persoonia 26:108-156

Crous PW, Shivas RG, Wingfield MJ, Summerell BA, Rossman AY, Alves JL, Adams GC, Barreto RW, Bell A, Coutinho ML, Flory SL, Gates G, Grice KR, Hardy GE, Kleczewski NM, Lombard L, Longa CM, Louis-Seize G, Macedo F, Mahoney DP, Maresi G, Martin-Sanchez PM, Marvanová L, Minnis AM, Morgado LN, Noordeloos ME, Phillips AJ, Quaedvlieg W, Ryan PG, Saiz-Jimenez C, Seifert KA, Swart WJ, Tan YP, Tanney JB, Thu PQ, Videira SI, Walker DM, Groenewald JZ (2012a) Fungal planet description sheets: 128-153. Persoonia 29:146-201

Crous PW, Summerell BA, Shivas RG, Burgess TI, Decock CA, Dreyer LL, Granke LL, Guest DI, Hardy GE, Hausbeck MK, Huberli D, Jung T, Koukol O, Lennox CL, Liew EC, Lombard L, McTaggart AR, Pryke JS, Roets F, Saude C, Shuttleworth LA, Stukely MJ, Vanky K, Webster BJ, Windstam ST, Groenewald JZ (2012b) Fungal planet description sheets: 107-127. Persoonia 28:138-182

Crous PW, Wingfield MJ, Guarro J, Cheewangkoon R, van der Bank M, Swart WJ, Stchigel AM, CanoLira JF, Roux J, Madrid H, Damm U, Wood AR, Shuttleworth LA, Hodges CS, Munster M, de Jesus YMM, Zúñiga-Estrada L, Cruywagen EM, de Hoog GS, Silvera C, Najafzadeh MJ, Davison EM, Davison PJN, Barrett MD, Barrett RL, Manamgoda DS, Minnis AM, Kleczewski NM, Flory SL, Castlebury LM, Clay K, Hyde KD, Maússe-Sitoe SND, Chen S, Lechat C, Hairaud M, Lesage-Meessen L, Pawłowska J, Wilk M, Śliwińska-Wyrzychowska A, Mętrak M, Wrzosek M, Pavlic-Zupanc D, Maleme HM, Slippers B, Mac Cormack WP, Archuby DI, Grünwald NJ, Tellería MT, Dueñas M, Martín MP, Marincowitz S, de Beer ZW, Perez CA, Gené J, Marin-Felix J, Groenewald JZ (2013) Fungal planet description sheets: 154-213. Persoonia 31:188-296

Crous PW, Wingfield MJ, Richardson DM, Leroux JJ, Strasberg D, Edwards J, Roets F, Hubka V, Taylor PWJ, Heykoop M, Martín MP, Moreno G, Sutton DA, Wiederhold NP, Barnes CW, Carlavilla JR, Gené J, Giraldo A, Guarnaccia V, Guarro J, Hernández-Restrepo M, Kolařík M, Manjón JL, Pascoe IG, Popov ES, Sandoval-Denis M, Woudenberg JHC, Acharya K, Alexandrova AV, Alvarado P, Barbosa RN, Baseia IG, Blanchette RA, Boekhout T, Burgess TI, Cano-Lira JF, Čmoková A, Dimitrov RA, Dyakov MY, Dueñas M, Dutta AK, Esteve-Raventós F, Fedosova AG, Fournier J, Gamboa P, Gouliamova DE, Grebenc T, Groenewald M, Hanse B, Hardy GESTJ, Held BW, Jurjević Ž, Kaewgrajang T, Latha KPD, Lombard L, Luangsa-ard JJ, Lysková P, Mallátová N, Manimohan P, Miller AN, Mirabolfathy M, Morozova OV, Obodai M, Oliveira NT, Ordóñez ME, Otto EC, Paloi S, Peterson SW, Phosri C, Roux J, Salazar WA, Sánchez A, Sarria GA, Shin H-D, Silva BDB, Silva GA, Smith MTH, Souza-Motta CM, Stchigel AM, Stoilova-Disheva MM, Sulzbacher MA, Telleria MT, Toapanta C, Traba JM, ValenzuelaLopez N, Watling R, Groenewald JZ (2016) Fungal planet description sheets: 400-468. Persoonia 36:316-458

Damm U, Fourie PH, Crous PW (2010) Coniochaeta (Lecythophora), Collophora gen. nov. and Phaeomoniella species associated with wood necroses of Prunus trees. Persoonia 24:60-80 
de Azevedo CMPS, Gomes RR, Vicente VA, Santos DWCL, Marques SG, do Nascimento MMF, Andrade CEW, Silva RR, Queiroz-Telles F, de Hoog GS (2015) Fonsecaea pugnacius, a novel agent of disseminated chromoblastomycosis. J Clin Microbiol 53:2674-2685

de Hoog GS, Hermanides-Nijhof EJ (1977) The black yeasts and allied Hyphomycetes. Stud Mycol $15: 1-222$

de Hoog GS, Weenink XO, Gerrits van den Ende AHG (1999a) Taxonomy of the Phialophora verrucosa complex with the description of two new species. Stud Mycol 43:107-121

de Hoog GS, Zalar P, Urzi C, Sterflinger K (1999b) Relationships of dothideaceous black yeasts and meristematic fungi based on 5.8S and ITS2 rDNA sequence comparison. Stud Mycol 43:31-37

de Hoog GS, Guarro J, Gené J, Figueras MJ (2000) Atlas of clinical fungi, 2nd Ed. Centraalbureau voor Schimmelcultures, Utrecht, The Netherlands, and Universitat Rovira i Virgili, Reus, Spain

de Hoog GS, Vicente VA, Caligiorne RB, Kantarcioglu S, Tintelnot K, Gerrits van den Ende AHG, Haase G (2003) Species diversity and polymorphism in the Exophiala spinifera clade containing opportunistic black yeast-like fungi. J Clin Microbiol 41:4767-4778

de Hoog GS, Attili-Angelis D, Vicente VA, Gerrits van den Ende AHG, Queiroz-Telles F (2004) Molecular ecology and pathogenic potential of Fonsecaea species. Med Mycol 42:405-416

de Hoog GS, Nishikaku AS, Fernandez-Zeppenfeldt G, Padín-González C, Burger E, Badali H, RichardYegres N, Gerrits van den Ende AHG (2007) Molecular analysis and pathogenicity of the Cladophialophora carrionii complex, with the description of a novel species. Stud Mycol 58:219-234

de Hoog GS, Vicente VA, Najafzadeh MJ, Harrak MJ, Badali H, Seyedmousavi S (2011) Waterborne Exophiala species causing disease in cold-blooded animals. Persoonia 27:46-72

de Hoog GS, Zeng JS, Harrak MJ, Sutton DA (2006) Exophiala xenobiotica sp. nov., an opportunistic black yeast inhabiting environments rich in hydrocarbons. Antonie Van Leeuwenhoek 90:257-268

de Vries GA (1962) Cyphellophora laciniata nov. gen., nov. sp. and Dactylium fusarioides Fragoso et Ciferri. Mycopathol Mycol Appl 16:47-54

Decock C, Delgado Rodríguez G, Buchet S, Seng JM (2003) A new species and three new combinations in Cyphellophora, with a note on the taxonomic affinities of the genus, and its relation to Kumbhamaya and Pseudomicrodochium. Antonie Van Leeuwenhoek 84:209-216

Diederich P, Ertz D, Lawrey JD, Sikaroodi M, Untereiner WA (2013) Molecular data place the hyphomycetous lichenicolous genus Sclerococcum close to Dactylospora (Eurotiomycetes) and $S$. parmeliae in Cladophialophora (Chaetothyriales). Fungal Divers 58:61-72

Dixon DM, Shadomy HJ, Shadomy S (1980) Dematiaceous fungal pathogens isolated from nature. Mycopathologia 70:153-161

Döğen A, Kaplan E, Oksüz Z, Serin MS, Ilkit M, de Hoog GS (2013) Dishwashers are a major source of human opportunistic yeast-like fungi in indoor environments in Mersin, Turkey. Med Mycol 51:493498 
Edgar RC (2004) MUSCLE: multiple sequence alignment with high accuracy and high throughput. Nucleic Acids Res 32:1792-1797

Feng PY, de Hoog GS, Najafzadeh MJ, Gerrits van den Ende AHG, Stielow JB, Badali H, Boeger WA, Vicente VA (2014) Cladophialophora abundans, a novel species of Chaetothyriales isolated from the natural environment. Mycol Prog 13:381-391

Feng P, Lu Q, Najafzadeh MJ, Gerrits van den Ende AHG, Sun J, Li R, Xi L, Vicente VA, Lai W, Lu C, de Hoog GS (2012) Cyphellophora and its relatives: biodiversity and possible role in human infection. Fungal Divers 65:17-45

Gams W (2000) Phialophora and some similar morphologically little-differentiated anamorphs of divergent ascomycetes. Stud Mycol 45:187-199

Gao L, Ma Y, Zhao W, Wei Z, Gleason ML, Chen H, Hao L, Sun G, Zhang R (2015) Three new species of Cyphellophora (Chaetothyriales) associated with sooty blotch and flyspeck. PLoS ONE 10:e0136857

Geiser DM, Gueidan C, Miadlikowska J, Lutzoni F, Kauff F, Hofsetter V, Fraker E, Schoch CL, Tibell L, Untereiner WA, Aproot A (2006) Eurotiomycetes: Eurotiomycetidae and Chaetothyriomycetidae. Mycologia 98:1053-1064

Gezuele E, Mackinnon JE, Conti-Díaz IA (1972) The frequent isolation of Phialophora verrucosa and Fonsecaea pedrosoi from natural sources. Sabouraudia 10:266-273

González-López MA, Salesa R, González-Vela MC, Fernández-Llaca H, Val-Bernal CJ (2007)

Subcutaneous phaeohyphomycosis caused by Exophiala oligosperma in a renal transplant patient. $\mathrm{Br}$ J Dermatol 156:748-791

Gueidan C, Villaseñor CR, de Hoog GS, Gorbushina AA, Untereiner WA, Lutzoni F (2008) A rockinhabiting ancestor for mutualistic and pathogen-rich fungal lineages. Stud Mycol 61:111-119

Gueidan C, Aptroot A, da Silva Cáceres ME, Badali H, Stenroos S (2014) A reappraisal of orders and families within the subclass Chaetothyriomycetidae (Eurotiomycetes, Ascomycota). Mycol Prog 13:1027-1039

Hallmann C, Wedekind W, Hause-Reitner D, Hoppert M (2013) Cryptogam covers on sepulchral monuments and re-colonization of a marble surface after cleaning. Environ Earth Sci 69:1149-1160

Harrington TC, McNew DL (2003) Phylogenetic analysis places the Phialophora-like anamorph genus Cadophora in the Helotiales. Mycotaxon 87:141-151

Irinyi L, Serena C, Garcia-Hermoso D, Arabatzis M, Desnos-Ollivier M, Vu D, Cardinali G, Arthur I, Normand AC, Giraldo A, da Cunha KC, Sandoval-Denis M, Hendrickx M, Nishikaku AS, de Azevedo Melo AS, Merseguel KB, Khan A, Parente Rocha JA, Sampaio P, da Silva Briones MR, e Ferreira RC, Medeiros Muniz M, Castañón-Olivares LR, Estrada-Barcenas D, Cassagne C, Mary C, Duan SY, Kong F, Sun AY, Zeng X, Zhao Z, Gantois N, Botterel F, Robbertse B, Schoch C, Gams W, Ellis D, Halliday C, Chen S, Sorrell TC, Piarroux R, Colombo AL, Pais C, de Hoog S, Zancopé-Oliveira RM, Taylor ML, Toriello C, de Almeida Soares CM, Delhaes L, Stubbe D, Dromer F, Ranque S, Guarro J, Cano-Lira JF, Robert V, Velegraki A, Meyer W (2015) International society of human and animal mycology (ISHAM)-ITS reference DNA barcoding database - the quality controlled standard tool for routine identification of human and animal pathogenic fungi. Med Mycol 53:313-337 
Isola D, Selbmann L, de Hoog GS, Fenice M, Onofri S, Prenafeta-Boldú FX, Zucconi L (2013) Isolation and screening of black fungi as degraders of volatile aromatic hydrocarbons. Mycopathologia 175:369-379

Iwatsu T (1984) A new species of Cladosporium from Japan. Mycotaxon 20:521-533

Iwen PC, Hinrichs SH, Rupp ME (2002) Utilization of the internal transcribed spacer regions as molecular targets to detect and identify human pathogens. Med Mycol 40:87-109

Jiang YL, Wang Y (2010) Two new species of Phialophora from Guizhou Province. Mycosystema 29:783-785

Kan T, Takahagi S, Kamegashira A, Ooiwa H, Yaguchi T, Hide M (2013) Disseminated subcutaneous phaeohyphomycosis caused by Exophiala oligosperma in a patient with Wegener's granulomatosis. Acta Derm Veneorol 93:356-357

Koukol O (2010) Revision of "Septonema ochraceum" revealed three new species of Venturiaceae and Herpotrichiellaceae. Mycol Prog 9:369-378

Lawrey JD, Diederich P, Ertz D, Sikaroodi M, Untereiner WA (2013) Molecular data place the hyphomycetous lichenicolous genus Sclerococcum close to Dactylospora (Eurotiomycetes) and $S$. parmeliae in Cladophialophora (Chaetothyriales). Fungal Divers 58:61-72

Li DM, Li RY, de Hoog GS, Sudhadham M, Wang DL (2011) Fatal Exophiala infections in China, with a report of seven cases. Mycoses 54:e136-e142

Li Y, Xiao J, de Hoog GS, Wang X, Wan Z, Yu J, Liu W, Li R (2017) Biodiversity and human pathogenicity of Phialophora verrucosa and relatives in Chaetothyriales. Persoonia 38:1-19

Liu JK, Hyde KD, Gareth Jones EB, Ariyawansa HA, Bhat DJ, Boonmee S, Maharachchikumbura SSN, McKenzie EHC, Phookamsak R, Phukhamsakda C, Shenoy BD, Abdel-Wahab MA, Buyck B, Chen J, Thilini Chethana KW, Singtripop C, Dai DQ, Dai YC, Daranagama DA, Dissanayake AJ, Doilom M, D'Souza MJ, Fan XL, Goonasekara ID, Hirayama K, Hongsanan S, Jayasiri SC, Jayawardena RS, Karunarathna SC, Li WJ, Mapook A, Norphanphoun C, Pang KL, Perera RH, Peršoh D, Pinruan U, Senanayake IC, Somrithipol S, Suetrong S, Tanaka K, Thambugala KM, Tian Q, Tibpromma S, Udayanga $\mathrm{D}$, Wijayawardene NN, Wanasinghe $\mathrm{D}$, Wisitrassameewong $\mathrm{K}$, Zeng $\mathrm{XY}$, Abdel-Aziz FA, Adamčík S, Bahkali AH, Boonyuen N, Bulgakov T, Callac P, Chomnunti P, Greiner K, Hashimoto A, Hofstetter V, Kang JC, Lewis D, Li XH, Liu XZ, Liu ZY (2015) Fungal diversity notes 1-110: taxonomic and phylogenetic contributions to fungal species. Fungal Divers 72:1-197

Maciá-Vicente JG, Glynou K, Piepenbring M (2016) A new species of Exophiala associated with roots. Mycol Prog 15:18

Matos T, de Hoog GS, de Boer AG, de Crom I, Haase G (2002) High prevalence of the neurotrope Exophiala dermatitidis and related oligotrophic black yeasts in sauna facilities. Mycoses 45:373-377

Matsushima T (1987) Matsushima mycological memoirs no. 5. Published by the author, Kobe, Japan Millar KR (1990) A new species of Phialophora from lake sediment. Mycologia 82:647-650 
Najafzadeh MJ, Sun J, Vicente V, Xi L, Gerrits van den Ende AHG, de Hoog GS (2010) Fonsecaea nubica sp. nov., a new agent of human chromoblastomycosis revealed using molecular data. Med Mycol 48:800-806

Najafzadeh MJ, Vicente VA, Sun J, Meis JF, de Hoog GS (2011) Fonsecaea multimorphosa sp. nov., a new species of Chaetothyriales isolated from a feline cerebral abscess. Fungal Biol 115:1066-1076

Najafzadeh MJ, Dolatabadi S, Saradeghi Keisari M, Naseri A, Feng P, de Hoog GS (2013) Detection and identification of opportunistic Exophiala species using the rolling cycle amplification of ribosomal internal transcribed spacers. J Microbiol Methods 94:338-342

Narisawa K, Hambleton S, Currah RS (2007) Heteroconium chaetospira, a dark septate root endophyte allied to the Herpotrichiellaceae (Chaetothyriales) obtained from some forest soil samples in Canada using bait plants. Mycoscience 48:274-281

Nepel M, VogImayr H, Schönenberger J, Mayer VE (2014) High diversity and low specificity of chaetothyrialean fungi in carton galleries in a neotropical ant-plant association. PLoS ONE 9:e112756

Nunes AT, Cavalcanti MA, de Queiroz LA (1999) Occurrence of Pseudomicrodochium suttonii in Brazil. Rev Microbiol 30:52-53

O'Donnell K (1993) Fusarium and its near relatives. In: Reynolds DR, Taylor JW (eds) The fungal holomorph: mitotic, meiotic and pleomorphic speciation in fungal systematics. CAB International, Wallingford, pp 225-233

Obase K, Douhan GW, Matsuda Y, Smith ME (2016) Cladophialophora floridana and Cladophialophora tortuosa, new species isolated from sclerotia of Cenococcum geophilum in forest soils of Florida, USA. Mycoscience 57:26-34

Park MJ, Shin HD (2011) Cladophialophora pucciniophila, a new hyphomycete parasitizing a rust fungus. Mycotaxon 116:449-456

Perfect JR, Schell WA (1996) The new fungal opportunists are coming. Clin Infect Dis 22(Suppl 2):8112-8118

Pratibha J, Prabhugaonkar A (2015) New record of Thysanorea papuana from India. Mycosphere 6:480-485

Prenafeta-Boldú FX, Kuhn A, Luykx DM, Anke H, van Groenenstijn JW, de Bont JAM (2001) Isolation and characterisation of fungi growing on volatile aromatic hydrocarbons as their sole carbon and energy source. Mycol Res 105:477-484

Prenafeta-Boldú FX, Summerbell RC, de Hoog GS (2006) Fungi growing on aromatic hydrocarbons: biotechnology's unexpected encounter with biohazard? FEMS Microbiol Rev 30:109-130

Rakeman JL, Bui U, Lafe K, Chen YC, Honeycutt RJ, Cookson BT (2005) Multilocus DNA sequence comparisons rapidly identify pathogenic molds. J Clin Microbiol 43:3324-3333

Réblová M, Untereiner WA, Réblová K (2013) Novel evolutionary lineages revealed in the Chaetothyriales (Fungi) based on multigene phylogenetic analyses and comparison of its secondary structure. PLOS ONE 28:e63547 
Salgado CG, da Silva JP, Diniz JA, da Silva MB, da Costa PF, Teixeira C, Salgado UI (2004) Isolation of Fonsecaea pedrosoi from thorns of Mimosa pudica, a probable natural source of chromoblastomycosis. Rev Inst Med Trop Sao Paulo 46:33-36

Satow MM, Attili-Angelis D, de Hoog GS, Angelis DF, Vicente VA (2008) Selective factors involved in oil flotation isolation of black yeasts from the environment. Stud Mycol 61:157-163

Schol-Schwarz MB (1970) Revision of the genus Phialophora (Moniliales). Persoonia 6:59-94

Seyedmousavi S, Badali H, Chlebicki A, Zhao J, Prenafeta-Boldú, de Hoog GS (2011) Exophiala sideris, a novel black yeast isolated from environments polluted with toxic alkyl benzenes and arsenic. Fungal Biol 115:1030-1037

Seyedmousavi S, Guillot J, de Hoog GS (2013) Phaeohyphomycoses, emerging opportunistic diseases in animals. Clin Microbiol Rev 26:19-35

Sudhadham M, Dorrestein GM, Prakitsin S, Sivichai S, Chaiyarat R, Menken SBJ, de Hoog GS (2008) The neurotropic black yeast Exophiala dermatitidis has a possible origin in the tropical rainforest. Stud Mycol 61:145-155

Tamura K, Stecher G, Peterson D, Filipski A, Kumar S (2013) MEGA6: molecular evolutionary genetics analysis version 6.0. Mol Biol Evol 30:2725-2729

Tsuneda A, Hambleton S, Currah RS (2011) The anamorph genus Knufia and its phylogenetically allied species in Coniosporium, Sarcinomyces and Phaeococcomyces. Botany 89:523-536

Untereiner WA, Naveau FA (1999) Molecular systematics of the Herpotrichiellaceae with an assessment of the phylogenetic positions of Exophiala dermatitidis and Phialophora americana. Mycologia 91:67-83

Untereiner WA, Angus A, Réblová M, Orr MJ (2008) The systematics of the Phialophora verrucosa complex: new insights from $\beta$-tubulin, large subunit nuclear rDNA and ITS sequence data. Botany $86: 742-750$

Vicente VA, Attili-Angelis D, Pie MR, Queiroz-Telles F, Cruz LM, Najafzadeh MJ, de Hoog GS, Zhao J, Pizzirani-Kleiner A (2008) Environmental isolation of black yeast-like fungi involved in human infection. Stud Mycol 61:137-144

Vicente VA, Orélis-Ribeiro R, Najafzadeh MJ, Sun J, Schier Guerra R, Miesch S, Ostrensky A, Meis JF, Klaassen CH, de Hoog GS, Boeger WA (2012) Black yeast-like fungi associated with lethargic crab disease (LCD) in the mangrove-land crab, Ucides cordatus (Ocypodidae). Vet Microbiol 158:109-122

Vicente VA, Najafzadeh MJ, Sun J, Gomes RR, Robl D, Marques SG, Azevedo CMPS, de Hoog GS (2014) Environmental siblings of black agents of human chromoblastomycosis. Fungal Divers 65:4763

Vijaykrishna D, Mostert L, Jeewon R, Gams W, Hyde KD, Crous PW (2004) Pleurostomophora, an anamorph of Pleurostoma (Calosphaeriales), a new anamorph genus morphologically similar to Phialophora. Stud Mycol 50:387-396 
Vitale RG, de Hoog GS (2002) Molecular diversity, new species and antifungal susceptibilities in the Exophiala spinifera clade. Med Mycol 40:545-556

Voglmayr H, Mayer V, Maschwitz U, Moog J, Djieto-Lordon C, Blatrix R (2011) The diversity of antassociated black yeasts: insights into a newly discovered world of symbiotic interactions. Fungal Biol 115:1077-1091

Weerakoon G, Aptroot A, Lumsch HT, Wolseley PA, Wijeyaratne SC, Gueidan C (2012) Molecular data on Pyrenulaceae from Sri Lanka reveal two well-supported groups within this family.

Lichenologist 44:639-647

Wen YM, Rajendran RK, Lin YF, Kirschner R, Hu S (2016) Onychomycosis associated with Exophiala oligosperma in Taiwan. Mycopathologia 181:83-88

White TJ, Bruns T, Lee S, Taylor JW (1990) Amplification and direct sequencing of fungal ribosomal RNA genes for phylogenetics. In: Innis MA, Gelfand DH, Shinsky JJ, White TJ (eds) PCR protocols: a guide to methods and applications. Academic, San Diego, pp 315-332

Woo PC, Ngan AH, Tsang CC, Ling IW, Chan JF, Leung SY, Yuen KY, Lau SK (2013) Clinical spectrum of Exophiala infections and a novel Exophiala species, E. hongkongensis. J Clin Microbiol 51:260-267

Wu Y-M, Zhang T-Y (2011) Two new species of Phialophora from soil. Mycotaxon 115:251-254

Yong LK, Wiederhold NP, Sutton DA, Sandoval-Denis M, Lindner JR, Fan H, Sanders C, Guarro J (2015) Morphological and molecular characterization of Exophiala polymorpha sp. nov., isolated from sporotrichoid lymphocutaneous lesions in a patient with myasthenia gravis. J Clin Microbiol 53:2816-2822

Zeng JS, de Hoog GS (2008) Exophiala spinifera and its allies: diagnostics from morphology to DNA barcoding. Med Mycol 46:193-208

Zeng JS, Sutton DA, Fothergill AW, Rinaldi MG, Harrak MJ, de Hoog GS (2007) Spectrum of clinically relevant Exophiala species in the United States. J Clin Microbiol 45:3713-3720

Zhao J, Zeng J, de Hoog GS, Attili-Angelis D, Prenafeta-Boldú FX (2010) Isolation of black yeasts by enrichment on atmospheres of monoaromatic hydrocarbons. Microb Ecol 60:149-156 